\title{
Effect of the time delay on the magnitude of the onset galloping wind speed in semiactive controlled suspension bridges
}

\author{
Mohamed Abdel-Rohman \\ Professor, Civil Engineering Department, Kuwait University \\ mabdelrohmang@gmail.com
}

Submitted: $04 / 03 / 2020$

Revised: $17 / 11 / 2020$

Accepted: $23 / 11 / 2020$

\begin{abstract}
To increase the onset galloping wind speed, after which galloping of the flexible suspension bridges occurs, resulting in the failure of these bridges due to wind, semiactive control mechanisms could be installed in the bridge to increase its damping. The time delay in processing the active control force and the actuator's dynamics are, however, major practical problems, which may affect the dynamic stability of the semiactive controlled structure. This paper shows the effect of the time delay on the magnitude of the onset galloping wind speed for a suspension bridge controlled by a semiactive control mechanism. It is shown that the time delay decreases the magnitude of the onset galloping wind speed. This makes the suspended cables in the suspension bridge susceptible for galloping, which may cause progressive collapse for the bridge at low mean wind speeds. This could be avoided if the active control force is designed considering the time delay effect.
\end{abstract}

Keywords: Active control force; Onset galloping wind speed; Nonlinear dynamics; Suspension bridges; Timedelay effect; Tuned mass damper; Wind-induced vibrations.

\section{INTRODUCTION}

During the past three decades, considerable attention was paid to the application of the active control devices to control the response of the flexible civil engineering structures when subjected to unexpected dynamic loading such as wind or earthquakes. Serious efforts were undertaken to develop and implement the structural control concept and today we have many such devices installed in a wide variety of civil engineering structures (Soong. and Spencer, 2002). Active, hybrid and semiactive control mechanisms are devices integrated with the real-time processing evaluators/ controllers and sensors in order to apply the active control forces on the structure. They act simultaneously with the unexpected dynamic loads excitations to provide enhanced structural behavior, which satisfies the safety and serviceability of the structure. 


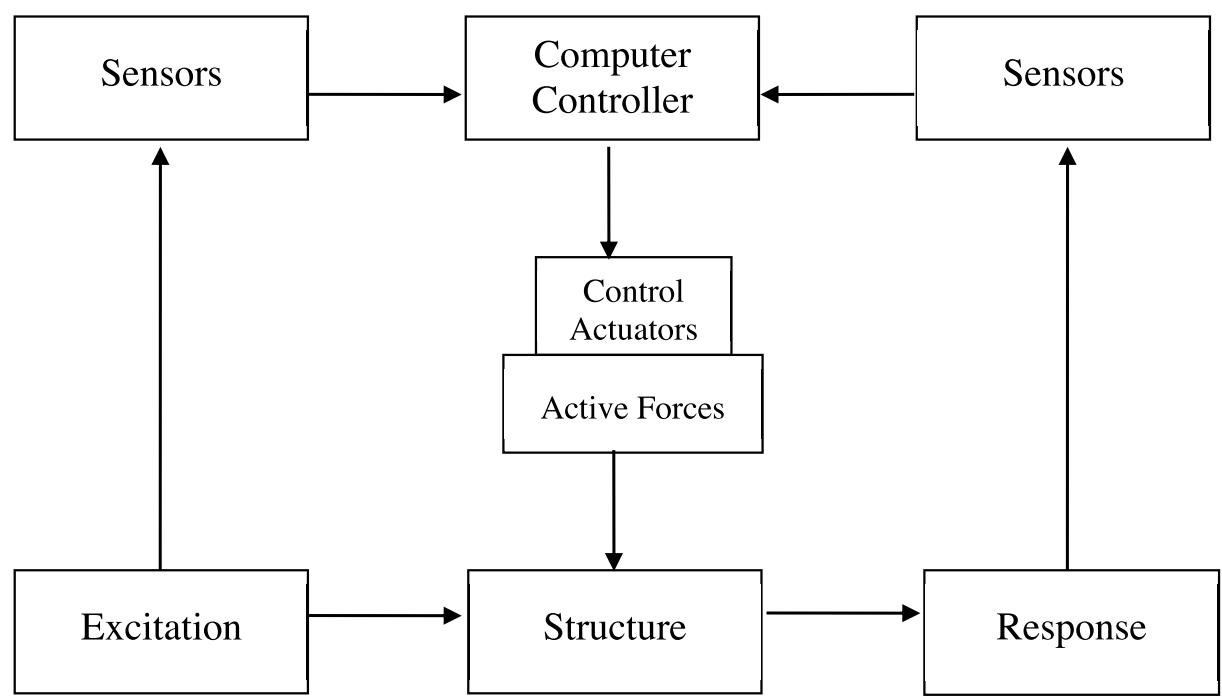

Figure 1. Schematic diagram for the semiactive control schemes.

An active structural controlled system has the basic configuration shown in Figure 1. It consists of (a) sensors located on the structure to measure either the external excitations, or the structural responses, or both; (b) devices to process the measured information and to compute the necessary control actions needed based on a designed control algorithm; and (c) electrohydraulic actuators, usually powered by external energy sources, to produce the required control forces.

Although too much work has been done on the theoretical development of the structural control algorithms, e.g., Soong and Spencer (2002) and Leipholz and Abdel-Rohman (1986), the implementation of these control strategies to real structures required resolution of practical important issues. A major important issue is the time-delay between receiving and sending the electrical signals. In the feedback control systems, the controlled response is monitored continuously, and the gathered information is processed to make continual regulations to the applied control forces. The total time delay in a controlled system is divided into two parts. The first part is a fixed time delay due to the online data acquisition, filtering, manipulation of the digital data inside the digital control processor, calculation of the required control forces, and the signals transmission from the computer to the actuators. This time delay part is generally negligible, because it is in the order of a few hundred millisecond. The second part of the time delay is due to the dynamic response of the actuators. The electromechanical or electrohydraulic actuators operations have dynamic effects, which result in time lags in the generation of the control actions. This time lag part is important and should be considered in the design of the control actions.

The importance of compensating the time delay effect in structural control has been demonstrated with experiments by many researchers. Several researchers proposed compensation methods for time delay, e.g., Chung et al. (1995), Abdel-Rohman (1985, 1987), Abdel-Rohman et al. (1993, 2010), Soliman and Ray (1992), Yang et al. (1990), Nayfeh et al. (2005), and Masoud et al. (2005).

This paper shows the effect of the time delay on the magnitude of the onset galloping wind speed for a suspension bridge controlled by a semiactive tuned mass damper mechanism. It is shown that the time delay decreases the magnitude of the onset galloping wind speed, causing the bridge to gallop or collapses at low mean wind. This indicates that the active control forces should be designed considering the time delay effect to ensure the safety and serviceability of the controlled structure. 


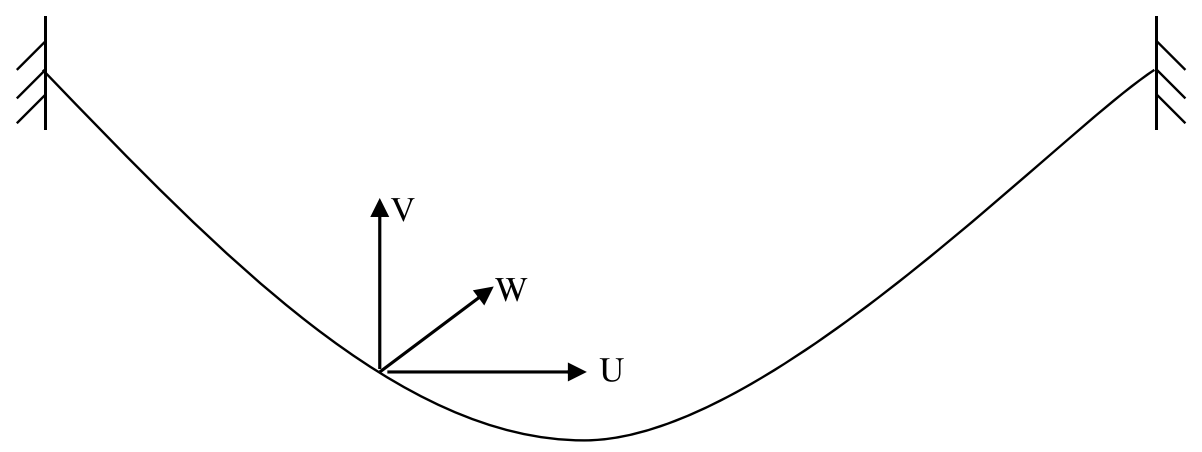

Figure 2. Displacements Directions in Suspended Cable.

\section{EQUATIONS OF MOTION}

The basic equations of motion of the suspended cables were defined by Irvine (1992). According to the displacements' directions defined in Figure 2, the general equations of motion are as follows:

$$
\begin{aligned}
& \frac{\partial}{\partial \mathrm{s}}\left[\left(\mathrm{T}_{\mathrm{O}}+\tau\right) \times \frac{\partial(\mathrm{x}+\mathrm{U})}{\partial \mathrm{s}}\right]=\mathrm{m} \times \frac{\partial^{2} \mathrm{U}}{\partial \mathrm{t}^{2}} \\
& \frac{\partial}{\partial \mathrm{s}}\left[\left(\mathrm{T}_{\mathrm{O}}+\tau\right) \times \frac{\partial(\mathrm{y}+\mathrm{V})}{\partial \mathrm{s}}\right]=-\mathrm{m} \times \mathrm{g}+\mathrm{m} \times \frac{\partial^{2} \mathrm{~V}}{\partial \mathrm{t}^{2}}+\mathrm{c} \times \frac{\partial \mathrm{V}}{\partial \mathrm{t}}+\mathrm{F}_{\mathrm{v}}(\mathrm{s}, \mathrm{t}) \\
& \frac{\partial}{\partial \mathrm{s}}\left[\left(\mathrm{T}_{\mathrm{O}}+\tau\right) \times \frac{\partial(\mathrm{W})}{\partial \mathrm{s}}\right]=\mathrm{m} \times \frac{\partial^{2} \mathrm{~W}}{\partial \mathrm{t}^{2}}+\mathrm{c} \times \frac{\partial \mathrm{W}}{\partial \mathrm{t}}+\mathrm{F}_{\mathrm{w}}(\mathrm{s}, \mathrm{t})
\end{aligned}
$$

in which (s) is the spatial coordinate along the cable curved length. The time is $(\mathrm{t})$. The coordinate along the cable horizontal span is (x). The cable static profile is $\mathrm{y}(\mathrm{s})$. The displacements in the horizontal, vertical, and transversal directions are, respectively, $\mathrm{U}(\mathrm{s}, \mathrm{t}), \mathrm{V}(\mathrm{s}, \mathrm{t})$, and $\mathrm{W}(\mathrm{s}, \mathrm{t})$. The static tension force in the cable is $\left(\mathrm{T}_{\mathrm{O}}\right)$. The additional dynamic tension force in the cable is $(\tau)$. The damping coefficient in the suspended cable is $(\mathrm{c})$. The external wind loading per unit length in the vertical and transverse directions are, respectively, $F_{v}(s, t)$ and $F_{w}(s, t)$.

The nonlinear strain relationship during the deformation of the suspended cable is given by:

$$
\frac{\tau}{\mathrm{EA}^{*}}=\frac{\mathrm{ds} \mathrm{s}^{\prime}-\mathrm{ds}}{\mathrm{ds}}
$$

where $(E)$ is the modulus of elasticity and $\left(\mathrm{A}^{*}\right)$ is the cross-section area of the cable.

The deformed cable segment (ds') and un-deformed cable segment (ds) are obtained as follows:

$$
\begin{aligned}
& d s^{2}=(d x+\partial U)^{2}+(d y+\partial V)^{2}+(\partial W)^{2} \\
& d s^{2}=d x^{2}+d y^{2}
\end{aligned}
$$

A two-hinged bridge deck is supported by suspended cables, using vertical hangers located at $\left(\mathrm{s}=\mathrm{s}_{\mathrm{i}}\right)$. A tuned mass damper is installed at the mid-span of the bridge deck. An active vertical control force $u(t)$ is applied on the tuned mass damper and the bridge deck, as shown in Figure 3. 


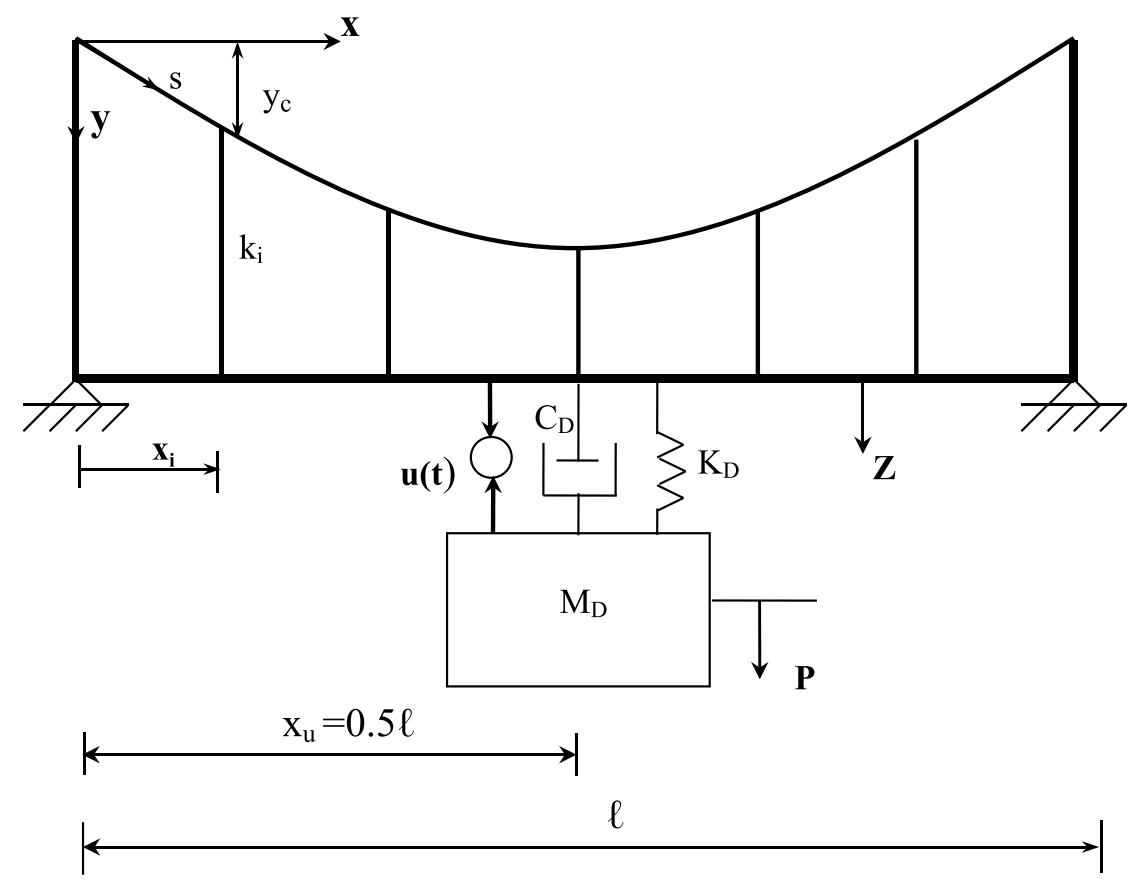

Figure 3. Suspension bridge model with a semiactive single TMD control mechanism.

Neglecting the horizontal motion $U(s, t)$, in the case of zero longitudinal loading, the equations of motion of the suspended cables and the bridge deck and the tuned mass damper with the active control force $u(t)$ can be written, based on the assumption of small curvature regime, as follows:

$$
\begin{aligned}
& \frac{\partial}{\partial \mathrm{s}}\left[\left(\mathrm{T}_{\mathrm{o}}+\tau\right) \times \frac{\partial \mathrm{W}}{\partial \mathrm{s}}\right]=\mathrm{m} \times \frac{\partial^{2} \mathrm{~W}}{\partial \mathrm{t}^{2}}+\mathrm{c} \times \frac{\partial \mathrm{W}}{\partial \mathrm{t}}+\mathrm{F}_{\mathrm{W}}(\mathrm{s}, \mathrm{t}) \\
& \frac{\partial}{\partial \mathrm{s}}\left[\left(\mathrm{T}_{\mathrm{o}}+\tau\right) \times \frac{\partial(\mathrm{y}+\mathrm{V})}{\partial \mathrm{s}}\right]=-\mathrm{m} \times \mathrm{g}+\mathrm{m} \times \frac{\partial^{2} \mathrm{~V}}{\partial \mathrm{t}^{2}}+\mathrm{c} \times \frac{\partial V}{\partial \mathrm{t}}+\mathrm{F}_{\mathrm{V}}(\mathrm{s}, \mathrm{t}) \\
& -\mathrm{u}(\mathrm{t}) \times \delta(\mathrm{s}-\overline{\mathrm{s}})-\sum_{\mathrm{i}=1}^{\mathrm{N}} \mathrm{k}_{\mathrm{i}} \times\left(\mathrm{Z}_{\mathrm{i}}-\mathrm{V}_{\mathrm{i}}\right) \times \delta\left(\mathrm{s}-\mathrm{s}_{\mathrm{i}}\right) \\
& \mathrm{EI} \frac{\partial^{4} \mathrm{Z}}{\partial \mathrm{x}^{4}}+\mathrm{c}_{\mathrm{b}} \frac{\partial \mathrm{Z}}{\partial \mathrm{t}}+\mathrm{m}_{\mathrm{b}} \frac{\partial^{2} \mathrm{Z}}{\partial \mathrm{t}^{2}}=\mathrm{F}_{\mathrm{wb}}(\mathrm{x}, \mathrm{t})-\sum_{\mathrm{i}=1}^{\mathrm{N}} \mathrm{k}_{\mathrm{i}} \times\left(\mathrm{Z}_{\mathrm{i}}-\mathrm{V}_{\mathrm{i}}\right) \times \delta\left(\mathrm{x}-\mathrm{x}_{\mathrm{i}}\right) \\
& \quad \mathrm{u}(\mathrm{t}) \times \delta(\mathrm{x}-\overline{\mathrm{x}})-\left[\mathrm{u}(\mathrm{t})+\mathrm{F}_{\mathrm{T}}\right] \times \delta(\mathrm{x}-0.5 \ell) \\
& \ddot{\mathrm{P}}+\mu_{\mathrm{D}} \times[\dot{\mathrm{P}}-\dot{\mathrm{Z}}(0.5 \ell, \mathrm{t})]+\omega_{\mathrm{D}}^{2} \times[\mathrm{P}-\mathrm{Z}(0.5 \ell, \mathrm{t})]=0 \\
& \mathrm{~F}_{\mathrm{T}}=\mathrm{M}_{\mathrm{D}} \times \mu_{\mathrm{D}} \times[\dot{\mathrm{P}}-\dot{\mathrm{Z}}(0.5 \ell, \mathrm{t})]+\mathrm{M}_{\mathrm{D}} \times \omega_{\mathrm{D}}^{2} \times[\mathrm{P}-\mathrm{Z}(0.5 \ell, \mathrm{t})]
\end{aligned}
$$

In equations (7) to (11), $\mathrm{P}(\mathrm{t})$ is the response of the tuned mass damper. The response of the bridge deck at the mid-span is $\mathrm{Z}(0.5 \ell, \mathrm{t})$. The flexural rigidity of the bridge deck is $(\mathrm{EI})$. The damping and mass per unit length for the bridge deck are, respectively, $\left(c_{b}\right)$ and $\left(m_{b}\right)$. The stiffness of the vertical hanger number (i), each is located at the 
distance $\left(\mathrm{x}_{\mathrm{i}}\right)$ and $\left(\mathrm{s}_{\mathrm{i}}\right)$ is $\left(\mathrm{k}_{\mathrm{i}}\right)$. The concentrated active control force $\mathrm{u}(\mathrm{t})$ is located at the mid-span. The vertical response of the bridge deck is $Z(x, t)$. The vertical response of the bridge deck $\left(Z_{i}\right)$ is located at $\left(x=x_{i}\right)$. The vertical response of the suspended cables $\left(\mathrm{V}_{\mathrm{i}}\right)$ is located at $\left(\mathrm{s}=\mathrm{s}_{\mathrm{i}}\right)$. The Dirac-Delta function $(\delta)$ is used to introduce the concentrated forces into the differential equations. The damping, the natural frequency and the mass of the tuned mass damper are, respectively, $\left(\mu_{\mathrm{D}}\right),\left(\omega_{\mathrm{D}}\right)$ and $\left(\mathrm{M}_{\mathrm{D}}\right)$. The wind forces on the cable in W-direction, the wind forces on the cable in $\mathrm{V}$-direction and the wind forces on the bridge deck in the vertical direction are denoted, respectively, by $\left(\mathrm{F}_{\mathrm{w}}\right),\left(\mathrm{F}_{\mathrm{v}}\right)$ and $\left(\mathrm{F}_{\mathrm{wb}}\right)$.

For simplicity, the displacement functions $\mathrm{W}(\mathrm{s}, \mathrm{t}), \mathrm{V}(\mathrm{s}, \mathrm{t})$ and $\mathrm{Z}(\mathrm{x}, \mathrm{t})$ are from the contribution of the first modes of vibrations. They are defined as follows:

$$
\begin{aligned}
& \mathrm{W}(\mathrm{s}, \mathrm{t})=\lambda(\mathrm{s}) \times \mathrm{W}(\mathrm{t}) \\
& \mathrm{V}(\mathrm{s}, \mathrm{t})=\phi(\mathrm{s}) \times \mathrm{V}(\mathrm{t}) \\
& \mathrm{Z}(\mathrm{x}, \mathrm{t})=\eta(\mathrm{x}) \times \mathrm{Z}(\mathrm{t})
\end{aligned}
$$

where $\lambda(\mathrm{s})$ and $\phi(\mathrm{s})$ are, respectively, the first mode shapes of the cable in the transversal and vertical directions. The mode shapes $\lambda(\mathrm{s})$ and $\phi(\mathrm{s})$ can be determined using the linear theory of cables (Irvine, 1992) to satisfy the boundary conditions. These mode shapes are defined as follows:

$$
\begin{aligned}
& \lambda(\mathrm{s})=\sin \left(\frac{\pi \mathrm{s}}{\ell^{*}}\right) \\
& \phi(\mathrm{s})=\mathrm{k}_{\mathrm{o}} \times\left[1-\tan \left(\frac{\mu \pi}{2}\right) \times \sin \left(\frac{\mu \pi \mathrm{s}}{\ell^{*}}\right)-\cos \left(\frac{\mu \pi \mathrm{s}}{\ell^{*}}\right)\right]
\end{aligned}
$$

where $\left(\mathrm{k}_{\mathrm{o}}\right)$ is a constant chosen to make $\left[\phi\right.$ at $\left.\mathrm{s}=\left(\ell^{*} / 2\right)=1\right]$ and $(\mu)$ is a constant to satisfy the boundary conditions.

For a two hinged bridge deck, the mode shape $\eta(x)$ is given by:

$$
\eta(s)=\sin \left(\frac{\pi x}{\ell}\right)
$$

Substituting equations (12)-(14) into equations (7)-(11) and applying an integral transformation, one obtains, respectively, the equations of motion of $\mathrm{W}(\mathrm{t}), \mathrm{V}(\mathrm{t}), \mathrm{Z}(\mathrm{t})$, and $\mathrm{P}(\mathrm{t})$ for a specific control force $\mathrm{u}(\mathrm{t})$ as follows:

$$
\begin{array}{r}
\ddot{\mathrm{W}}+2 \zeta \omega_{\mathrm{w}} \dot{\mathrm{W}}+\omega_{\mathrm{w}}^{2} \mathrm{~W}+\mathrm{c}_{5} \mathrm{WV}+\mathrm{c}_{6} \mathrm{~W} \mathrm{~V}^{2}+\mathrm{c}_{7} \mathrm{~W}^{3}=\mathrm{F}_{\mathrm{w}}(\mathrm{t}) \\
\ddot{\mathrm{V}}+2 \zeta \omega_{\mathrm{v}} \dot{\mathrm{V}}+\omega_{\mathrm{v}}^{2} \mathrm{~V}+\mathrm{c}_{1} \mathrm{~V}^{2}+\mathrm{c}_{2} \mathrm{~W}^{2}+\mathrm{c}_{3} \mathrm{~V}^{3}+\mathrm{c}_{4} \mathrm{~V} \mathrm{~W}^{2}=\mathrm{F}_{\mathrm{v}}(\mathrm{t}) \\
+\mathrm{c}_{11} \times \mathrm{u}(\mathrm{t})+\mathrm{d}_{1} \mathrm{Z}+\mathrm{d}_{2} \mathrm{~V} \\
\ddot{\mathrm{Z}}+2 \zeta_{\mathrm{B}} \omega_{\mathrm{B}} \dot{\mathrm{Z}}+\omega_{\mathrm{B}}^{2} \mathrm{Z}=\mathrm{F}_{\mathrm{wb}}(\mathrm{t})+\mathrm{c}_{8} \times \mathrm{Z}+\mathrm{c}_{9} \times \mathrm{V}-\mathrm{c}_{10} \times \mathrm{u}(\mathrm{t}) \\
-\mathrm{c}_{10} \times\left[\mathrm{M}_{\mathrm{D}} \times 2 \zeta_{\mathrm{D}} \omega_{\mathrm{D}} \times(\dot{\mathrm{P}}-\dot{\mathrm{Z}})+\mathrm{M}_{\mathrm{D}} \times \omega_{\mathrm{D}}^{2} \times(\mathrm{P}-\mathrm{Z})\right] \\
\ddot{\mathrm{P}}+2 \zeta_{\mathrm{D}} \omega_{\mathrm{D}} \times \dot{\mathrm{P}}+\omega_{\mathrm{D}}^{2} \times \mathrm{P}=2 \zeta_{\mathrm{D}} \omega_{\mathrm{D}} \times \dot{\mathrm{Z}}+\omega_{\mathrm{D}}^{2} \times \mathrm{Z}-\mathrm{c}_{11} \times \mathrm{u}(\mathrm{t})
\end{array}
$$




\section{WIND LOADING ON THE CABLES}

The aerodynamic forces on the suspended cables due to wind in the transverse direction can be estimated from the along-wind and across-wind forces (Simiu and Scanlan, 1996, Holmes, 2015) as follows:

$$
\begin{aligned}
& \mathrm{F}_{\mathrm{w}}(\mathrm{s}, \mathrm{t})=\frac{1}{2} \times \rho \times \mathrm{D} \times \mathrm{U}_{\text {rel }}^{2}\left(\mathrm{C}_{\mathrm{D}} \cos \gamma-\mathrm{C}_{\mathrm{L}} \sin \gamma\right) \\
& \mathrm{F}_{\mathrm{v}}(\mathrm{s}, \mathrm{t})=-\frac{1}{2} \times \rho \times \mathrm{D} \times \mathrm{U}_{\text {rel }}^{2}\left(\mathrm{C}_{\mathrm{D}} \sin \gamma+\mathrm{C}_{\mathrm{L}} \cos \gamma\right)
\end{aligned}
$$

where $(\rho)$ is the air density, (D) is the cable diameter, $\left(C_{D}\right)$ is the wind drag coefficient, $\left(C_{L}\right)$ is the wind lift coefficient, $(\gamma)$ is the angle of attack, and $\left(U_{\text {rel }}\right)$ is the relative wind speed.

The relative wind speed with respect to the cable motion is expressed as follows:

$$
\mathrm{U}_{\text {rel }}^{2}(\mathrm{~s}, \mathrm{t})=\left[\mathrm{U}_{\mathrm{o}}(\mathrm{s}, \mathrm{t})-\dot{\mathrm{W}}(\mathrm{s}, \mathrm{t})\right]^{2}+\dot{\mathrm{V}}^{2}(\mathrm{~s}, \mathrm{t})
$$

in which $\mathrm{U}_{\mathrm{o}}(\mathrm{s}, \mathrm{t})$ is the mean wind speed, $\dot{\mathrm{W}}(\mathrm{s}, \mathrm{t})$ is the velocity of the cable in the transverse direction $\mathrm{W}$, and $\dot{V}(s, t)$ is the velocity response of the cable in the vertical direction $\mathrm{V}$.

From Figure 4, one obtains the following relationships:

$$
\begin{aligned}
& \mathrm{U}_{\mathrm{o}}(\mathrm{s}, \mathrm{t})-\dot{\mathrm{W}}(\mathrm{s}, \mathrm{t})=\mathrm{U}_{\text {rel }}(\mathrm{s}, \mathrm{t}) \times \cos \gamma \\
& \dot{\mathrm{V}}(\mathrm{s}, \mathrm{t})=\mathrm{U}_{\text {rel }}(\mathrm{s}, \mathrm{t}) \times \sin \gamma
\end{aligned}
$$

$$
\operatorname{Tan} \gamma=\frac{\dot{\mathrm{V}}(\mathrm{s}, \mathrm{t})}{\mathrm{U}_{\mathrm{o}}(\mathrm{s}, \mathrm{t})-\dot{\mathrm{W}}(\mathrm{s}, \mathrm{t})}
$$

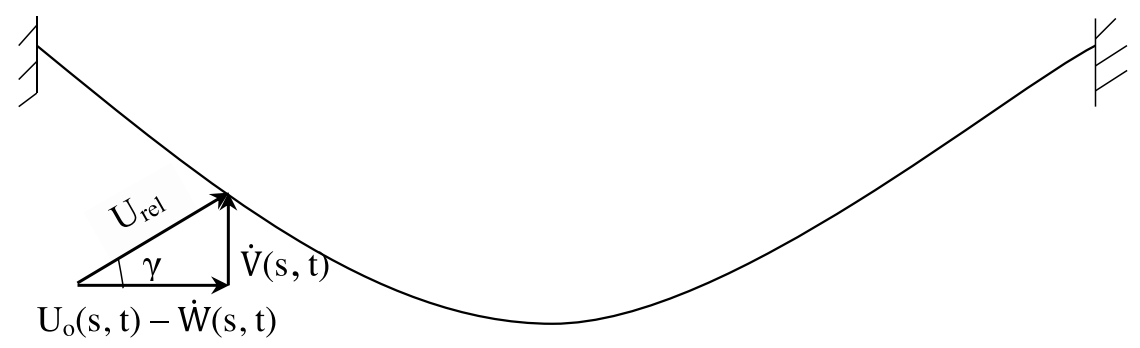

Figure 4. Directions of wind speed vectors.

Equations (22) and (23) can be expressed as follows:

$$
\begin{aligned}
& \mathrm{F}_{\mathrm{w}}(\mathrm{s}, \mathrm{t})=\frac{1}{2} \times \rho \times \mathrm{D} \times\left[\mathrm{U}_{\mathrm{o}}(\mathrm{s}, \mathrm{t})-\dot{\mathrm{W}}(\mathrm{s}, \mathrm{t})\right]^{2} \times \mathrm{C}_{\mathrm{w}}(\gamma) \\
& \mathrm{F}_{\mathrm{v}}(\mathrm{s}, \mathrm{t})=-\frac{1}{2} \times \rho \times \mathrm{D} \times\left[\mathrm{U}_{\mathrm{o}}(\mathrm{s}, \mathrm{t})-\dot{\mathrm{W}}(\mathrm{s}, \mathrm{t})\right]^{2} \times \mathrm{C}_{\mathrm{v}}(\gamma)
\end{aligned}
$$

where $C_{W}(\gamma)$ and $C_{V}(\gamma)$ are the wind force functions, defined as follows:

$$
\begin{aligned}
& C_{w}(\gamma)=\sec ^{2} \gamma \times\left(C_{D} \times \cos \gamma-C_{L} \times \sin \gamma\right) \\
& C_{v}(\gamma)=\sec ^{2} \gamma \times\left(C_{D} \times \sin \gamma+C_{L} \times \cos \gamma\right)
\end{aligned}
$$


The wind force function $\mathrm{C}_{\mathrm{w}}(\gamma)$ and $\mathrm{C}_{\mathrm{V}}(\gamma)$ are usually obtained from the wind tunnel tests. Curves that best fit the wind tunnel tests data are used in the analysis. This study is based on the results of the wind tunnel tests of (Korlin \& Starossek, 2007 and (Yu et al., 1993).

These wind force functions can be expressed as polynomials in $(\tan \gamma)$ as follows:

$$
\begin{aligned}
& \mathrm{C}_{\mathrm{w}}(\gamma)=\sum_{\mathrm{i}=1}^{\mathrm{N}} \mathrm{a}_{\mathrm{i}} \times \tan ^{\mathrm{i}} \gamma \\
& \mathrm{C}_{\mathrm{v}}(\gamma)=\sum_{\mathrm{i}=1}^{\mathrm{N}} \mathrm{b}_{\mathrm{i}} \times \tan ^{\mathrm{i}} \gamma
\end{aligned}
$$

where $(\mathrm{N})$ is the degree of the polynomial, and $\left(\mathrm{a}_{\mathrm{i}}\right)$ and $\left(\mathrm{b}_{\mathrm{i}}\right)$ are constants to be determined from the wind tunnel tests data.

Substituting equations (28) to (31) into equations (22) and (23), the expression of $\mathrm{F}_{\mathrm{w}}(\mathrm{t})$ in equation (18) and the expression of $F_{v}(t)$ in equation (19) are as derived by (Abdel-Rohman and Spencer, 2004) from the following equations:

$$
\begin{aligned}
& \mathrm{F}_{\mathrm{w}}(\mathrm{t})=\frac{\int_{0}^{\ell^{*}} \lambda(\mathrm{s}) \times \mathrm{F}_{\mathrm{w}}(\mathrm{s}, \mathrm{t}) \mathrm{ds}}{\mathrm{m}_{c} \times \int_{0}^{\ell^{*}} \lambda^{2}(\mathrm{~s}) \mathrm{ds}} \\
& \mathrm{F}_{\mathrm{v}}(\mathrm{t})=\frac{\int_{0}^{\ell^{*}} \phi(\mathrm{s}) \times \mathrm{F}_{\mathrm{v}}(\mathrm{s}, \mathrm{t}) \mathrm{ds}}{\mathrm{m}_{c} \times \int_{0}^{\ell^{*}} \phi^{2}(\mathrm{~s}) \mathrm{ds}}
\end{aligned}
$$

Using equations (24) to (33) into equations (34) and (35), we obtain the following equations:

$$
\begin{aligned}
\mathrm{F}_{\mathrm{w}}(\mathrm{t})= & \mathrm{C}_{\mathrm{wo}}+\mathrm{C}_{\mathrm{w} 1} \dot{\mathrm{W}}+\mathrm{C}_{\mathrm{w} 2} \dot{\mathrm{W}}^{2}+\mathrm{C}_{\mathrm{w} 3} \dot{\mathrm{V}}+\mathrm{C}_{\mathrm{w} 4} \dot{\mathrm{W}} \dot{\mathrm{V}}+\mathrm{C}_{\mathrm{w} 5} \dot{\mathrm{V}}^{2} \\
& +\sum_{\mathrm{k}=3}^{\mathrm{N}} \mathrm{C}_{\mathrm{w}(2 \mathrm{k})} \dot{\mathrm{V}}^{\mathrm{k}}+\sum_{\mathrm{k}=3}^{\mathrm{N}} \mathrm{C}_{\mathrm{w}(2 \mathrm{k}+1)} \dot{\mathrm{V}}^{\mathrm{k}} \dot{\mathrm{W}}^{(\mathrm{k}-2)} \\
\mathrm{F}_{\mathrm{v}}(\mathrm{t})= & \mathrm{C}_{\mathrm{vo}}+\mathrm{C}_{\mathrm{v} 1} \dot{\mathrm{W}}+\mathrm{C}_{\mathrm{v} 2} \dot{\mathrm{W}}^{2}+\mathrm{C}_{\mathrm{v} 3} \dot{\mathrm{V}}+\mathrm{C}_{\mathrm{v} 4} \dot{\mathrm{W}} \times \dot{\mathrm{V}}+\mathrm{C}_{\mathrm{v} 5} \dot{\mathrm{V}}^{2} \\
& +\sum_{\mathrm{k}=3}^{\mathrm{N}} \mathrm{C}_{\mathrm{v}(2 \mathrm{k})} \dot{\mathrm{V}}^{\mathrm{k}}+\sum_{\mathrm{k}=3}^{\mathrm{N}} \mathrm{C}_{\mathrm{v}(2 \mathrm{k}+1)} \dot{\mathrm{V}}^{\mathrm{k}} \times \dot{\mathrm{W}}^{(\mathrm{k}-2)}
\end{aligned}
$$

where the coefficients $\mathrm{C}_{\mathrm{wi}}$ and $\mathrm{C}_{\mathrm{vi}}$ are calculated using the equations defined in the appendix.

\section{WIND LOADING ON THE BRIDGE DECK}

One may consider the wind forces due to any effect on the bridge deck. In this paper, the self-exciting wind forces due to vortex shedding on the bridge deck are considered. In this case, the wind force on the bridge deck $F_{w b}(t)$ in equation (20) is obtained using the following equation (Simiu and Scanlan, 1996):

$$
\mathrm{F}_{\mathrm{wb}}(\mathrm{x}, \mathrm{t})=\frac{1}{2} \times \rho \times \mathrm{U}^{2}(\mathrm{x}, \mathrm{t}) \times 2 \mathrm{~B}_{\mathrm{b}} \times \mathrm{H}^{*} \times\left(1-\varepsilon \times \frac{\mathrm{Z}^{2}(\mathrm{x}, \mathrm{t})}{\mathrm{B}_{\mathrm{b}}^{2}}\right) \times\left(\frac{\dot{\mathrm{Z}}(\mathrm{x}, \mathrm{t})}{\mathrm{U}(\mathrm{x}, \mathrm{t})}\right)
$$

in which $\mathrm{U}(\mathrm{x}, \mathrm{t})$ is the mean wind speed on the bridge deck, $\left(\mathrm{B}_{\mathrm{b}}\right)$ is the bridge deck width, and $\left(\mathrm{H}^{*}\right)$ and $(\varepsilon)$ are the aerodynamic coefficients determined from the wind tunnel tests. 
Assuming a constant mean wind speed $\left[\mathrm{U}(\mathrm{x}, \mathrm{t})=\mathrm{U}_{\mathrm{o}}\right]$ at the level of the bridge deck, one obtains from the integral transformation the wind force component on the bridge deck as follows:

$$
\mathrm{F}_{\mathrm{wb}}(\mathrm{t})=\int \mathrm{F}_{\mathrm{wb}}(\mathrm{x}, \mathrm{t}) \times \eta(\mathrm{x}) \times \mathrm{dx}=\mathrm{c}_{12} \times \dot{\mathrm{Z}}-\mathrm{c}_{13} \times \dot{\mathrm{Z}} \times \mathrm{Z}^{2}
$$

in which $\left(\mathrm{c}_{12}\right)$ and $\left(\mathrm{c}_{13}\right)$ are constants calculated from the equations defined in the appendix.

\section{NUMERICAL EXAMPLE}

The two-hinged bridge deck of span $(\ell)$ is suspended from the cables using vertical hangers located at spacing $\left(s=s_{i}\right)$. A tuned mass damper (TMD), which can be excited by a vertical active control force $u(t)$, as shown in Figure 3 , is installed at the mid-span of the bridge deck $(\mathrm{x}=0.5 \ell)$. The equations of motion (18) to (21) including the time delay $(\tau)$ in the control force $\mathrm{u}(\mathrm{t})$ become:

$$
\begin{gathered}
\ddot{\mathrm{W}}+2 \zeta \omega_{\mathrm{w}} \times \dot{\mathrm{W}}+\omega_{\mathrm{w}}^{2} \times \mathrm{W}+\mathrm{c}_{5} \times \mathrm{WV}+\mathrm{c}_{6} \times \mathrm{WV}^{2}+\mathrm{c}_{7} \times \mathrm{W}^{3}=\mathrm{F}_{\mathrm{w}}(\mathrm{t}) \\
\ddot{\mathrm{V}}+2 \zeta \omega_{\mathrm{v}} \times \dot{\mathrm{V}}+\omega_{\mathrm{v}}^{2} \times \mathrm{v}+\mathrm{c}_{1} \mathrm{~V}^{2}+\mathrm{c}_{2} \mathrm{~W}^{2}+\mathrm{c}_{3} \mathrm{~V}^{3}+\mathrm{c}_{4} \mathrm{~V} \mathrm{~W}^{2}= \\
\mathrm{F}_{\mathrm{v}}(\mathrm{t})+\mathrm{d}_{1} \times \mathrm{Z}+\mathrm{d}_{2} \times \mathrm{V} \\
\ddot{\mathrm{Z}}+2 \zeta_{\mathrm{B}} \omega_{\mathrm{B}} \times \dot{\mathrm{Z}}+\omega_{\mathrm{B}}^{2} \times \mathrm{Z}=\mathrm{F}_{\mathrm{wb}}(\mathrm{t})+\mathrm{c}_{8} \times \mathrm{Z}+\mathrm{c}_{9} \times \mathrm{V}-\mathrm{c}_{10} \times \mathrm{u}(\mathrm{t}-\tau) \\
-\mathrm{c}_{10} \times\left[\mathrm{M}_{\mathrm{D}} \times 2 \zeta_{\mathrm{D}} \omega_{\mathrm{D}} \times(\dot{\mathrm{P}}-\dot{\mathrm{Z}})+\mathrm{M}_{\mathrm{D}} \times \omega_{\mathrm{D}}^{2} \times(\mathrm{P}-\mathrm{Z})\right] \\
\ddot{\mathrm{P}}+2 \zeta_{\mathrm{D}} \omega_{\mathrm{D}} \times \dot{\mathrm{P}}+\omega_{\mathrm{D}}^{2} \times \mathrm{P}=2 \zeta_{\mathrm{D}} \omega_{\mathrm{D}} \times \dot{\mathrm{Z}}+\omega_{\mathrm{D}}^{2} \times \mathrm{Z}-\mathrm{c}_{11} \times \mathrm{u}(\mathrm{t}-\tau)
\end{gathered}
$$

The natural frequencies of the cable in the transverse and vertical directions, the natural frequency in the bridge deck in the vertical directions are represented, respectively, by the symbols $\omega_{\mathrm{w}}, \omega_{\mathrm{v}}$ and $\omega_{\mathrm{B}}$. The damping ratio in the cable, the bridge deck and the damper are represented, respectively, by the symbols $\zeta, \zeta_{\mathrm{B}}$, and $\zeta_{\mathrm{D}}$. The coefficients $\mathrm{c}_{1}$ to $\mathrm{c}_{11}, \mathrm{~d}_{1}$ and $d_{2}$ are defined in the appendix, which were derived in (Abdel-Rohman and John, 2006). The notations $F_{w}(t), F_{v}(t)$ and $F_{w b}(t)$ represent, respectively, the generalized lateral wind force, the generalized vertical wind forces on the suspended cable and the generalized vertical wind force on the bridge deck, as given by equations (36), (37) and (39).

The aerodynamic forces on the cables depend on the air density, $\rho$, the cable diameter, $\mathrm{D}$, the drag coefficient, $\mathrm{C}_{\mathrm{D}}$, the lift coefficient, $C_{L}$, the angle of attack, $\gamma$, and the mean wind speed, $\mathrm{U}_{\mathrm{o}}(\mathrm{s}, \mathrm{t})$.

The numerical application is on the Great Belt Suspension Bridge (Huynh and Thoft-Christensen, 2001). The details of the bridge deck, the cables and wind parameters are as given in Table 1.

Table 1. Details of the Great Belt Suspension Bridge.

\begin{tabular}{|l|c|l|c|c|c|}
\hline \multicolumn{2}{|c|}{ Bridge deck } & \multicolumn{2}{c|}{ Cable } & \multicolumn{2}{c|}{ Wind Parameters } \\
\hline Span, $\mathrm{L}$ & $2500 \mathrm{~m}$ & Suspended length, $\ell$ & $2573 \mathrm{~m}$ & Air density, $\rho$ & $1.25 \mathrm{~kg} / \mathrm{m}^{3}$ \\
\hline Deck mass, $\mathrm{m}_{\mathrm{b}}$ & $14908 \mathrm{~kg} / \mathrm{m}$ & Cable mass, $\mathrm{m}$ & $4396 \mathrm{~kg} / \mathrm{m}$ & $\mathrm{H}^{*}$ & 1.7 \\
\hline Width $\mathrm{B}_{\mathrm{b}}$ & $27 \mathrm{~m}$ & Cable sag, $\mathrm{y}_{\mathrm{c}}$ & $265 \mathrm{~m}$ & $\varepsilon$ & 100 \\
\hline Flexural rigidity, EI & $2.4 \mathrm{E} 16 \mathrm{~N} \cdot \mathrm{m}^{2}$ & Cross sectional Area, A & $0.56 \mathrm{~m}^{2}$ & & \\
\hline $\begin{array}{l}\text { Stiffness of vertical } \\
\text { hangers, } \mathrm{k}_{\mathrm{i}}\end{array}$ & $\begin{array}{c}1 \mathrm{E} 6 \mathrm{~N} / \mathrm{m} \\
\text { (placed at every } 10 \mathrm{~m} \text { ) }\end{array}$ & $\begin{array}{l}\text { Young's Modulus of } \\
\text { Elasticity, E }\end{array}$ & $2.1 \mathrm{E} 11 \mathrm{~N} / \mathrm{m}^{2}$ & & \\
\hline Damping ratio, $\xi_{\mathrm{b}}$ & $1 \%$ & Damping ratio, $\zeta$ & $0.1 \%$ & & \\
\hline
\end{tabular}


The drag and wind force functions were obtained from fitting the wind tunnel data for U-shape cables as given by (Yu et al. 1993, Korlin, and Starossek, 2007). The wind tunnel data are fitted by seventh degree polynomials as follows:

$$
\begin{aligned}
\mathrm{C}_{\mathrm{w}}(\gamma)= & \sum_{\mathrm{i}=1}^{7} \mathrm{a}_{\mathrm{i}} \times \tan ^{\mathrm{i}} \gamma \\
\mathrm{C}_{\mathrm{w}}(\gamma)= & 1.17754+0.3544 \tan \gamma+0.61685 \tan ^{2} \gamma-0.0834 \tan ^{3} \gamma-0.11802 \tan ^{4} \gamma \\
& \quad+0.004687 \tan ^{5} \gamma+0.0031 \tan ^{6} \gamma-0.000075 \tan ^{7} \gamma \\
\mathrm{C}_{\mathrm{v}}(\gamma)= & \sum_{\mathrm{i}=1}^{7} \mathrm{~b}_{\mathrm{i}} \times \tan ^{\mathrm{i}} \gamma \\
\mathrm{C}_{\mathrm{v}}(\gamma)= & -0.14825-1.36225 \tan \gamma+0.39288 \tan ^{2} \gamma+2.0595 \tan ^{3} \gamma-0.1129 \tan ^{4} \gamma \\
& \quad-0.54836 \tan ^{5} \gamma+0.003134 \tan ^{6} \gamma+0.0151 \tan ^{7} \gamma
\end{aligned}
$$

in which the values of the constants in equation (44) represent the coefficients $\left(a_{i}\right)$ in the appendix and the constants in equation (45) represent the coefficients $\left(b_{i}\right)$ in the appendix, for $i=0,1,2 \ldots$ up to 7 .

According to the wind speed profile $\mathrm{U}_{\mathrm{o}}(\mathrm{s}, \mathrm{t})$, one can determine the coefficients $\mathrm{C}_{\mathrm{wi}}$ and $\mathrm{C}_{\mathrm{v}}$, for $\mathrm{i}=1$ up to 25 , from the equations defined in the Appendix.

\section{THE TIME DELAY EFFECT}

To study the time delay effect, we consider the active control force $\mathrm{u}(\mathrm{t})$ is generated from the semiactive TMD control mechanism, which is shown in Figure 3. This mechanism generates a single active control force proportional to the velocity response of the first mode of the bridge deck at the location of the damper $\left(x=x_{u}=0.5 \ell\right)$. The control force $u(t)$ is expressed as follows:

$$
\mathrm{u}(\mathrm{t})=\alpha \times \eta\left(\mathrm{x}_{\mathrm{u}}\right) \times \dot{\mathrm{Z}}(\mathrm{t})
$$

where $(\alpha)$ is the gain factor to be determined for the proper design of the active control force $u(t)$ and $\eta\left(x_{u}\right)$ is the magnitude of the mode shape $\eta(x)$ at the location $x=x_{u}=0.5 \ell$. The value of $(\alpha)$ is determined with the objective of safeguarding the structure from galloping at high wind speeds ( $\mathrm{Li}$ et al., 2017) by raising the magnitude of the onset galloping wind speed to a value more than any expected mean wind speed. In the presence of the time delay $(\tau)$ between the measured velocity response and applying the active control force, the control force is expressed as follows:

$$
\mathrm{u}(\mathrm{t}-\tau)=\alpha \times \eta\left(\mathrm{x}_{\mathrm{u}}\right) \times \dot{\mathrm{Z}}(\mathrm{t}-\tau)
$$

Using Taylor Series Expansion, considering the time delay $(\tau)$ is small, the control force $u(t-\tau)$ can be expressed as follows:

$$
\begin{aligned}
& u(t-\tau)=\left[u(t)-\tau \times \dot{u}(t)+\frac{\tau^{2}}{2} \times \ddot{u}(t)-\frac{\tau^{3}}{6} \times \dddot{u}(t)+\cdots\right] \\
& u(t-\tau)=\alpha \times \eta\left(x_{u}\right) \times\left[\dot{Z}(t)-\tau \times \ddot{Z}(t)+\frac{\tau^{2}}{2} \times \dddot{Z}(t)-\frac{\tau^{3}}{6} \times \ldots .\right]
\end{aligned}
$$

For a TMD located at the mid-span of the bridge deck, $x_{u}=0.5 \ell, \eta\left(x_{u}=0.5 \ell\right)=1.0$. Considering the first three terms of equation (49), equations (40) to (43) are expressed in the state space form, $\dot{\mathbf{X}}=\mathbf{A} \mathbf{X}+\mathbf{F}$, where $\mathbf{F}$ contains all the nonlinear terms, which do not have any contribution in the determination of the onset galloping wind speed. The state vector $\underline{\mathbf{X}}$ and the state matrix $\underline{\mathbf{A}}$ are defined as follows: 


$$
\begin{aligned}
& \mathbf{X}^{\mathrm{T}}=\left[\begin{array}{lcccccccc}
\mathrm{W} & \dot{\mathrm{W}} & \mathrm{V} & \dot{\mathrm{V}} & \mathrm{Z} & \dot{\mathrm{Z}} & \ddot{\mathrm{Z}} & \mathrm{P} & \dot{\mathrm{P}}
\end{array}\right] \\
& \mathbf{A}=\left[\begin{array}{ccccccccc}
0 & 1 & 0 & 0 & 0 & 0 & 0 & 0 & 0 \\
-\omega_{\mathrm{w}}^{2} & -\mu_{\mathrm{w}}+\mathrm{C}_{\mathrm{w} 1} & 0 & \mathrm{C}_{\mathrm{w} 3} & 0 & 0 & 0 & 0 & 0 \\
0 & 0 & 0 & 1 & 0 & 0 & 0 & 0 & 0 \\
0 & -\mathrm{C}_{\mathrm{v} 1} & -\omega_{\mathrm{v}}^{2}+\mathrm{d}_{2} & -\left(\mu_{\mathrm{v}}+\mathrm{C}_{\mathrm{v} 3}\right) & \mathrm{d}_{1} & 0 & 0 & 0 & 0 \\
0 & 0 & 0 & 0 & 0 & 1 & 0 & 0 & 0 \\
0 & 0 & 0 & 0 & 0 & 0 & 1 & 0 & 0 \\
0 & 0 & \mathrm{~A}(7,3) & 0 & \mathrm{~A}(7,5) & \mathrm{A}(7,6) & \mathrm{A}(7,7) & \mathrm{A}(7,8) & \mathrm{A}(7,9) \\
0 & 0 & 0 & 0 & 0 & 0 & 0 & 0 & 1 \\
0 & 0 & \mathrm{~A}(9,3) & 0 & \mathrm{~A}(9,5) & \mathrm{A}(9,6) & \mathrm{A}(9,7) & \mathrm{A}(9,8) & \mathrm{A}(9,9)
\end{array}\right]
\end{aligned}
$$

where

$$
\begin{aligned}
& \mathrm{R}_{1}=\frac{2}{\mathrm{c}_{10} \times \alpha \times \tau^{2}} ; \mathrm{A}(7,3)=\mathrm{c}_{9} \times \mathrm{R}_{1} \\
& A(7,5)=-\left(-\omega_{B}^{2}+c_{8}+c_{10} \times M_{D} \times \omega_{D}^{2}\right) \times R_{1} \\
& A(7,6)=-\left(-\mu_{B}+c_{12}+c_{10} \times M_{D} \times \mu_{D}-c_{10}\right) \times R_{1} ; \\
& A(7,7)=\left(c_{10} \times \alpha \times \tau-1\right) \times R_{1} \\
& A(7,8)=\left(-c_{10} \times M_{D} \times \omega_{D}^{2}\right) \times R_{1} ; \quad A(7,9)=\left(-c_{10} \times M_{D} \times \mu_{D}\right) \times R_{1} \\
& A(9,3)=-\frac{c_{11}}{c_{10}} \times c_{9} ; \quad A(9,5)=\omega_{D}^{2}-\frac{c_{11}}{c_{10}} \times\left(-\omega_{b}^{2}+c_{8}+c_{10} \times M_{D} \times \omega_{D}^{2}\right) \\
& A(9,6)=\mu_{D}-c_{11} \times \alpha-\frac{c_{11}}{c_{10}} \times\left(-\mu_{B}+c_{12}+c_{10} \times M_{D} \times \mu_{D}-c_{10} \times \alpha\right) \\
& A(9,7)=c_{11} \times \alpha \times \tau-\frac{c_{11}}{c_{10}} \times\left(c_{10} \times \alpha \times \tau-1\right) ; \\
& A(9,8)=-\omega_{D}^{2}+\frac{c_{11}}{c_{10}} \times\left(c_{10} \times M_{D} \times \omega_{D}^{2}\right) ; \\
& A(9,9)=-\mu_{D}+\frac{c_{11}}{c_{10}} \times\left(c_{10} \times M_{D} \times \mu_{D}\right) ; \\
& \mu_{B}=2 \times \zeta_{B} \times \omega_{B} ; \mu_{D}=2 \times \zeta_{D} \times \omega_{D}
\end{aligned}
$$

By inspecting the equations of motion (40) to (43), we observe that the nonlinear terms are more involved in the across-wind direction than in the along-wind direction, as indicated in the wind forces of equations (36) and (37). The steady state response of the structure at any mean wind speed $U_{o}$ can be determined from solving equations (40) to (43) numerically for any specific mean wind speed, $U_{0}$, and using any arbitrary initial conditions. The galloping steadystate amplitude will result in whenever the assumed mean wind speed exceeds the onset galloping wind speed. The onset galloping wind speeds $U_{c r}$ can be determined by searching for the magnitude of the mean wind speed $U_{0}$, which makes the linear system to be on the instability boundary (Den Hartog, 1932, 1985, Almutairy et al., 2011). 
The mean wind speed $U_{0}$, which makes the eigenvalues of the matrix $\underline{\mathbf{A}}$ start to have positive real values, is the onset galloping wind speed $\mathrm{U}_{\mathrm{cr}}$. The galloping occurs when the mean wind speed exceeds the onset galloping wind speed.

\section{OBSERVATION}

Table 2. The Onset Mean Wind Speed for Time Delay $\tau=0.15$ seconds.

\begin{tabular}{|c|c|c|c|c|c|}
\hline $\begin{array}{c}\text { Time-delay } \\
\boldsymbol{\tau}(\mathbf{s})\end{array}$ & $\begin{array}{c}\text { Wind Speed, } \\
\mathbf{U}_{\mathbf{0}}(\mathbf{m} / \mathbf{s})\end{array}$ & \multicolumn{4}{|c|}{ Eigenvalues of Matrix A } \\
\hline \multirow{6}{*}{30} & $-0.0047 \pm 0.4349 \mathrm{i}$ & $-0.0243 \pm 5.2211 \mathrm{i}$ & $-0.2683 \pm 2.8382 \mathrm{i}$ & $-0.2287 \pm 1.8894 \mathrm{i}$ \\
\cline { 2 - 6 } & 40 & $-0.0061 \pm 0.4348 \mathrm{i}$ & $-0.0201 \pm 5.2215 \mathrm{i}$ & $-0.2516 \pm 2.8358 \mathrm{i}$ & $-0.2286 \pm 1.8918 \mathrm{i}$ \\
\cline { 2 - 6 } & 50 & $-0.0075 \pm 0.4348 \mathrm{i}$ & $-0.0159 \pm 5.2219 \mathrm{i}$ & $-0.2349 \pm 2.8333 \mathrm{i}$ & $-0.2286 \pm 1.8942 \mathrm{i}$ \\
\cline { 2 - 6 } & 60 & $-0.0089 \pm 0.4348 \mathrm{i}$ & $-0.0117 \pm 5.2222 \mathrm{i}$ & $-0.2181 \pm 2.8308 \mathrm{i}$ & $-0.2287 \pm 1.8966 \mathrm{i}$ \\
\cline { 2 - 6 } & 70 & $-0.0103 \pm 0.4348 \mathrm{i}$ & $-0.0075 \pm 5.2224 \mathrm{i}$ & $-0.2012 \pm 2.8281 \mathrm{i}$ & $-0.2288 \pm 1.8990 \mathrm{i}$ \\
\cline { 2 - 6 } & 80 & $-0.0117 \pm 0.4347 \mathrm{i}$ & $-0.0033 \pm 5.2255 \mathrm{i}$ & $-0.1843 \pm 2.8255 \mathrm{i}$ & $-0.2290 \pm 1.9014 \mathrm{i}$ \\
\cline { 2 - 6 } & 85 & $-0.0125 \pm 0.4347 \mathrm{i}$ & $-0.0012 \pm 5.2226 \mathrm{i}$ & $-0.1758 \pm 2.8241 \mathrm{i}$ & $-0.2292 \pm 1.9026 \mathrm{i}$ \\
\cline { 2 - 6 } & $\mathbf{8 8}$ & $\mathbf{- 0 . 0 1 2 9} \pm \mathbf{0 . 4 3 4 7 i}$ & $+\mathbf{0 . 0 0 0 1} \pm \mathbf{5 . 2 2 2 6 i}$ & $\mathbf{- 0 . 1 7 0 7} \pm \mathbf{2 . 8 2 3 3 i}$ & $\mathbf{- 0 . 2 2 9 3} \pm \mathbf{1 . 9 0 3 3 i}$ \\
\cline { 2 - 6 } & 90 & $-0.0132 \pm 0.4347 \mathrm{i}$ & $+0.0010 \pm 5.2226 \mathrm{i}$ & $-0.1673 \pm 2.8227 \mathrm{i}$ & $-0.2293 \pm 1.9038 \mathrm{i}$ \\
\hline
\end{tabular}

Abdel-Rohman and John (2006) have selected the gain factor $(\alpha)$ to be $(\alpha=-5 \mathrm{e} 6)$, which raised the critical mean wind speed from $\left(U_{\mathrm{cr}}=33 \mathrm{~m} / \mathrm{s}\right)$, for the passive TMD controlled suspension bridge, to $\left(U_{\mathrm{cr}}=98 \mathrm{~m} / \mathrm{s}\right)$, for the semiactive controlled suspension bridge, assuming the time delay $(\tau=0)$. The effect of the time-delay due to the actuator dynamics on the critical mean wind speed was studied by determining the eigenvalues of the matrix $\underline{\mathbf{A}}$ of equation (51) for various values of time delays. The mean wind speed, at which the eigenvalues of the matrix $\underline{\mathbf{A}}$ have some positive real part, indicates a critical mean wind speed. The eigenvalues of matrix $\underline{\mathbf{A}}$ when the time delay is $\tau=0.15$ second are shown in Table 2. The eigenvalues for the time delay $\tau=0.20$ second are shown in Table 3 .

Table 3. The Onset Mean Wind Speed for Time Delay $\tau=0.20$ seconds.

\begin{tabular}{|c|c|c|c|c|c|}
\hline $\begin{array}{c}\text { Time-delay } \\
\boldsymbol{\tau}(\mathbf{s})\end{array}$ & $\begin{array}{c}\text { Wind Speed, } \\
\mathbf{U}_{\mathbf{0}}(\mathbf{m} / \mathbf{s})\end{array}$ & \multicolumn{4}{|c|}{ Eigenvalues of Matrix A } \\
\hline \multirow{6}{*}{} & 30 & $-0.0047 \pm 0.4349 \mathrm{i}$ & $-0.0198 \pm 5.2303 \mathrm{i}$ & $-0.2628 \pm 2.8725 \mathrm{i}$ & $-0.2274 \pm 1.8796 \mathrm{i}$ \\
\cline { 2 - 6 } & 40 & $-0.0061 \pm 0.4348 \mathrm{i}$ & $-0.0155 \pm 5.2307 \mathrm{i}$ & $-0.2461 \pm 2.8700 \mathrm{i}$ & $-0.2272 \pm 1.8819 \mathrm{i}$ \\
\cline { 2 - 6 } & 50 & $-0.0075 \pm 0.4348 \mathrm{i}$ & $-0.0111 \pm 5.2310 \mathrm{i}$ & $-0.2294 \pm 2.8675 \mathrm{i}$ & $-0.2271 \pm 1.8842 \mathrm{i}$ \\
\cline { 2 - 6 } 0.20 & 60 & $-0.0089 \pm 0.4348 \mathrm{i}$ & $-0.0067 \pm 5.2311 \mathrm{i}$ & $-0.2125 \pm 2.8648 \mathrm{i}$ & $-0.2270 \pm 1.8865 \mathrm{i}$ \\
\cline { 2 - 6 } & 70 & $-0.0103 \pm 0.4348 \mathrm{i}$ & $-0.0023 \pm 5.2313 \mathrm{i}$ & $-0.1957 \pm 2.8621 \mathrm{i}$ & $-0.2270 \pm 1.8889 \mathrm{i}$ \\
\cline { 2 - 6 } & 75 & $-0.0110 \pm 0.4348 \mathrm{i}$ & $-0.0010 \pm 5.2313 \mathrm{i}$ & $-0.1872 \pm 2.8607 \mathrm{i}$ & $-0.2270 \pm 1.8901 \mathrm{i}$ \\
\cline { 2 - 6 } & $\mathbf{7 6}$ & $\mathbf{- 0 . 0 1 1 2} \pm \mathbf{0 . 4 3 4 7 i}$ & $+\mathbf{0 . 0 0 0 3} \pm \mathbf{5 . 2 3 1 3 i}$ & $\mathbf{- 0 . 1 8 5 5} \pm \mathbf{2 . 8 6 0 5 i}$ & $\mathbf{- 0 . 2 2 7 0} \pm \mathbf{1 . 8 9 0 3 i}$ \\
\cline { 2 - 6 } & 80 & $-0.0117 \pm 0.4347 \mathrm{i}$ & $+0.0021 \pm 5.2313 \mathrm{i}$ & $-0.1788 \pm 2.8593 \mathrm{i}$ & $-0.2271 \pm 1.8912 \mathrm{i}$ \\
\hline
\end{tabular}


The eigenvalues, which contain negative real parts, indicate a stable controlled structure with no galloping. The value of the mean wind speed, at which the real part of some eigenvalues starts to shift towards the positive region, indicates the onset galloping wind speed.

It is observed from Table 2 that, for the time delay $\tau=0.15$ second, some eigenvalues shift to the positive real parts at the mean wind speed, $U_{o}=88 \mathrm{~m} / \mathrm{s}$. Table 3 shows that, for the time delay $\tau=0.2$ second, some eigenvalues shift to the positive real parts at the mean wind speed, $U_{\mathrm{o}}=76 \mathrm{~m} / \mathrm{s}$. Therefore, the time-delay of 0.15 second has reduced the onset galloping wind speed, $\mathrm{U}_{\mathrm{cr}}$, from $98 \mathrm{~m} / \mathrm{s}$ (for $\tau=0$ ) to $88 \mathrm{~m} / \mathrm{s}$ (for $\tau=0.15$ second). For the time-delay $(\tau=0.2$ second), the onset galloping wind speed, $U_{c r}$, decreased from $98 \mathrm{~m} / \mathrm{s}$ to $76 \mathrm{~m} / \mathrm{s}$. For the mean wind speed $U_{o}=85 \mathrm{~m} / \mathrm{s}$, which is less than $U_{\text {cr }}=88 \mathrm{~m} / \mathrm{s}$ for $(\tau=0.15$ second), the bridge does not gallop as shown in Figures 5 and 6 . For the mean wind speed $U_{o}=90 \mathrm{~m} / \mathrm{s}$, which is greater than $U_{\mathrm{cr}}=88 \mathrm{~m} / \mathrm{s}$ for $(\tau=0.15$ second $)$, the bridge gallops as shown in Figures 7 and 8. The same observation applies for the time delay $\left(\tau=0.2\right.$ second), which makes $U_{\mathrm{cr}}=76 \mathrm{~m} / \mathrm{s}$. We notice that the time delay $(\tau)$ resulting from the actuator dynamics reduces the magnitude of the onset galloping wind speed $\mathrm{U}_{\mathrm{cr}}$ and this reduction increases as the magnitude of the time delay $(\tau)$ increases.

\section{CONCLUSION}

The time delay is a major practical problem, which should be considered for the efficient performance of the active and semiactive controlled structures. In this paper, the active control force was developed from the feedback of the velocity response of the bridge deck at the mid-span. The time delay due to applying the designed active control force reduces the onset galloping wind speed, and this may destabilize the controlled structure. It has been shown that increasing the magnitude of the time-delay will cause further reduction in the magnitude of the onset galloping wind speed. Therefore, it is necessary to consider the effect of the time delay during the design of the active control force to guarantee the safety and serviceability of the controlled structure.

\section{ACKNOWLEDGMENT}

The Research Administration of Kuwait University, under grant number EV01/05, has financially supported this research project.
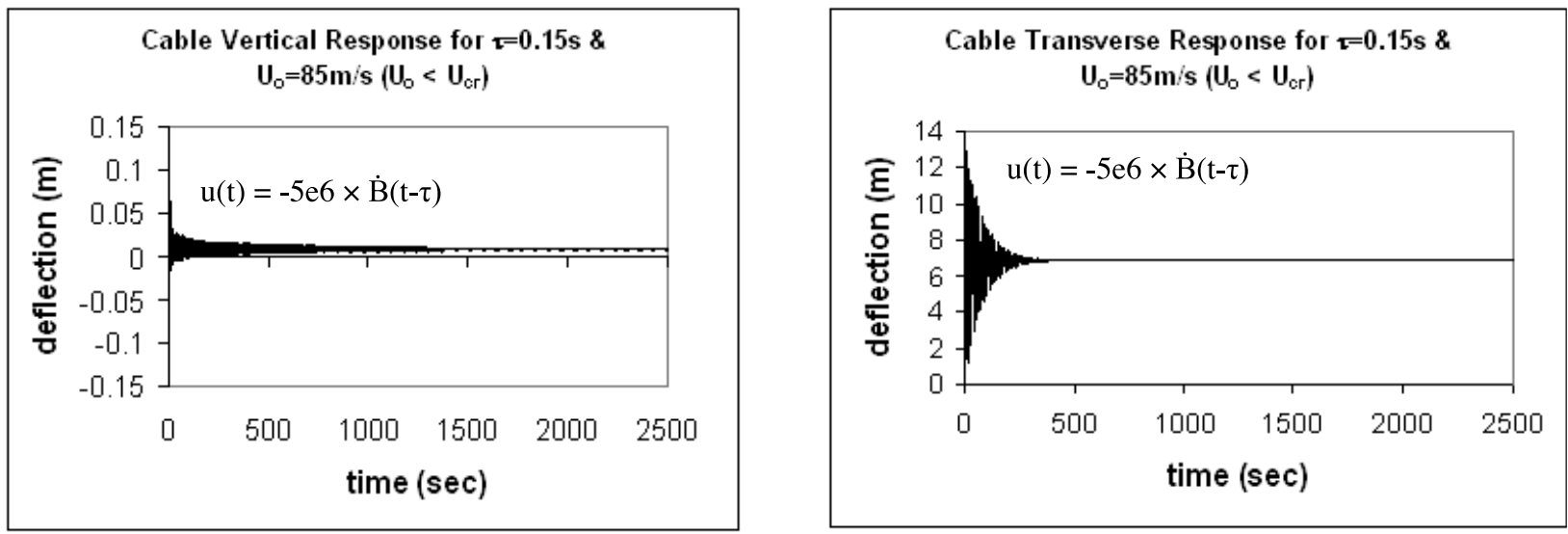

Figure 5. Cable Transverse and Vertical Responses when $\tau=0.15 \mathrm{sec}$. for $\mathrm{U}_{\mathrm{o}}=85 \mathrm{~m} / \mathrm{s}<\mathrm{U}_{\mathrm{cr}}=88 \mathrm{~m} / \mathrm{s}$. 

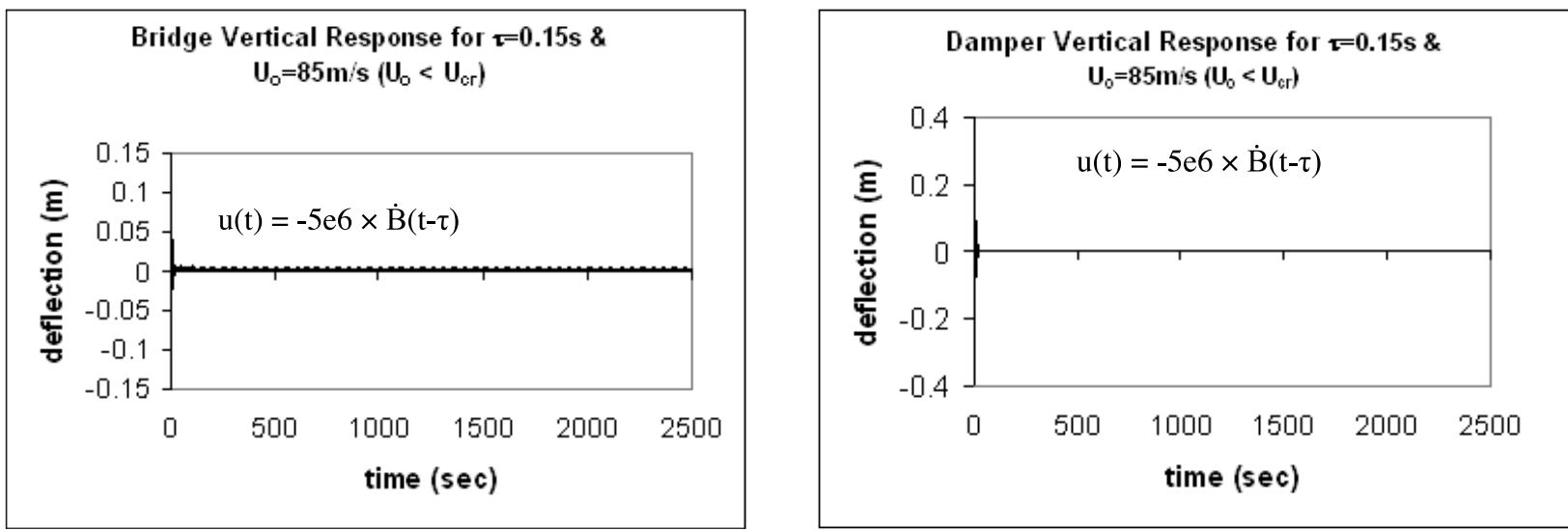

Figure 6. Bridge Deck and Damper Vertical Responses when $\tau=0.15 \mathrm{sec}$. for $U_{\mathrm{o}}=85 \mathrm{~m} / \mathrm{s}<U_{c r}=88 \mathrm{~m} / \mathrm{s}$.
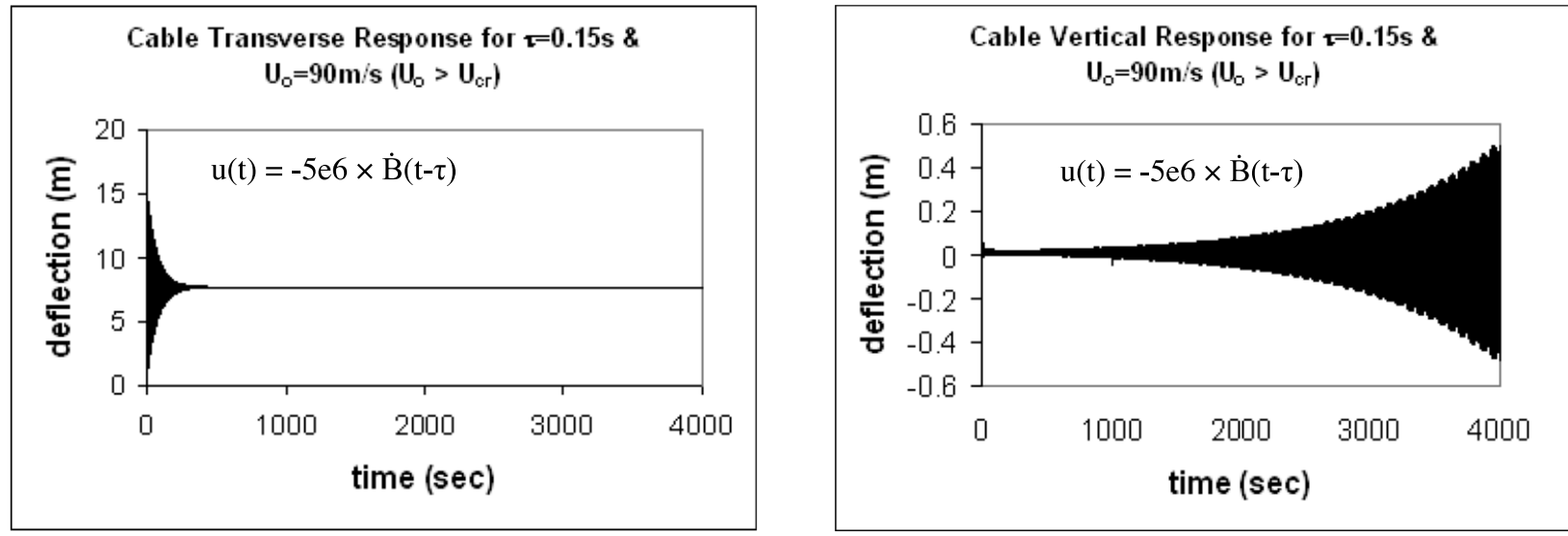

Figure 7. Cable Transverse and Vertical Responses when $\tau=0.15 \mathrm{sec}$. for $U_{\mathrm{o}}=90 \mathrm{~m} / \mathrm{s}>\mathrm{U}_{\mathrm{cr}}=88 \mathrm{~m} / \mathrm{s}$.
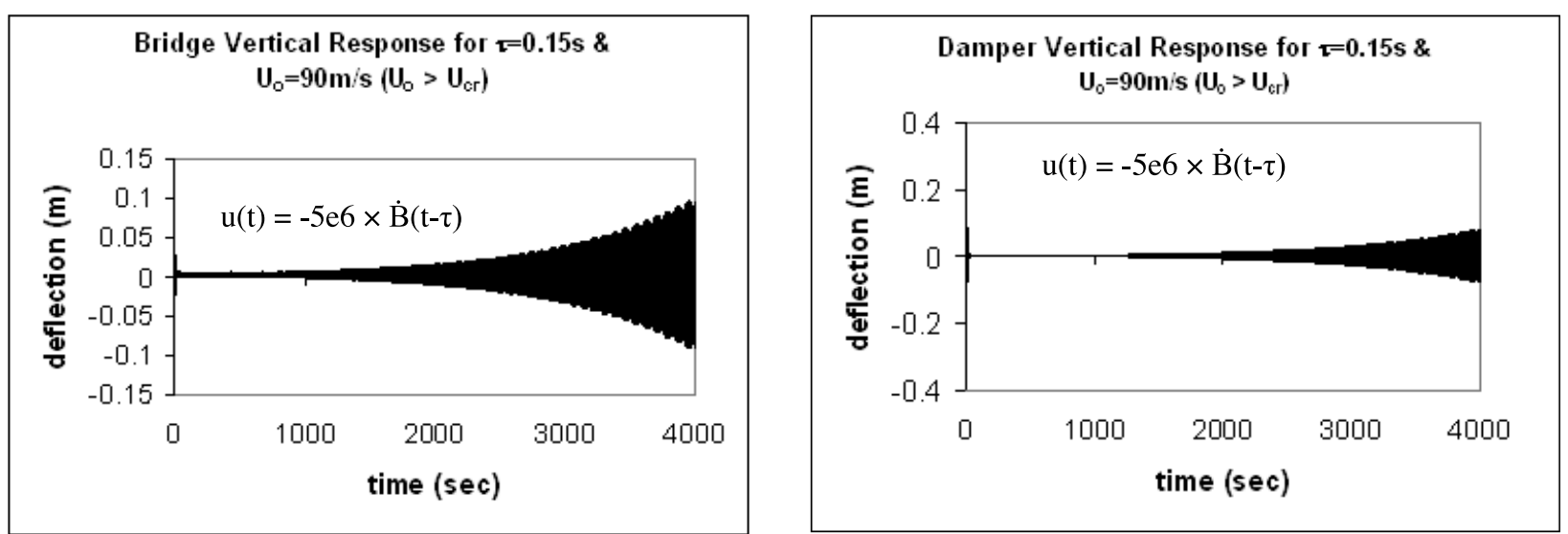

Figure 8. Bridge Deck and Damper Vertical Responses when $\tau=0.15 \mathrm{sec}$. for $U_{\mathrm{o}}=90 \mathrm{~m} / \mathrm{s}>U_{\mathrm{cr}}=88 \mathrm{~m} / \mathrm{s}$. 


\section{REFERENCES}

Abdel-Rohman, M. \& Spencer, B.F. 2004. Control of Wind-Induced Nonlinear Oscillations in Suspended Cables. Nonlinear Dynamics, 37: 341-355.

Abdel-Rohman, M. 1985. Structural Control Considering Time-Delay Effect. Transactions of Canadian Society of Mechanical Engineering, 9(4): 224-227.

Abdel-Rohman, M. 1987. Time-Delay Effects on Actively Damped Systems. Journal of Engineering Mechanics. ASCE 113(11): 1709-1719.

Abdel-Rohman, M., Sebakhy, O.A. \& Al-Halabi, M. 1993. Identification and Control of Flexible Civil Structures with TimeDelays. Computers and Structures, 47(6): 977-986.

Abdel-Rohman, M., John, M.J. \& Hassan, M.F. 2010. Compensation of Time Delay Effect in Semi-Active Controlled Suspension Bridges. Journal of Vibration and Control. Vol. 16, No. 10, pp. 1527-1558.

Abdel-Rohman, M. \& John, M.J. 2006. Control of Wind Induced Non-Linear Oscillations in Suspension Bridges using Multiple Semi-Active Tuned Mass Dampers. Journal of Vibrations and Control, 12(9): 1011-1046.

Abdel-Rohman, M. \& John, M.J. 2006. Control of Wind Induced Non-Linear Oscillations in Suspension Bridges using a SemiActive Tuned Mass Damper. Journal of Vibrations and Control, 12(10): 1049-1080.

Almutairi, N.B., Zribi, M. \& Abdel-Rohman, M. 2011. Lyapunov-Based Control for Suppression of Wind-Induced Galloping in Suspension Bridges. Mathematical problems in Engineering, 07.

Chung, L.L., Lin, R.C. \& Lu, K.H. 1995. Time-Delay Control of Structures. Earthquake Engineering and Structural Dynamics, 24(5): 687-701.

Den Hartog, J.P. 1932. Transmission line vibration due to sleet. American Institute of Electrical Engineers, 51(4): 1074-1081.

Den Hartog, J.P. 1985. Mechanical Vibrations. Dover Publications.

Holmes, J.D., 2015. Wind Loading of Structures. CRC Press.

Huynh, T. \& Thoft-Christensen, P. 2001. Suspension Bridge Flutter for Girders with Separate Control Flaps. Journal of Bridge Engineering ASCE 6(3): 168-175.

Irvine, M., 1992. Cable Structures. Dover Publications, Inc. New York.

Korlin, R. \& Starossek, U. 2007. Wind tunnel test of an active mass damper for bridge decks. Journal of Wind Engineering and Industrial Aerodynamics, 95(4): 267-277.

Leipholz, H.H. \& Abdel-Rohman, M. 1986. Control of Structures. Martinus Nijhoff Publishers, Boston, U.S.A.

Li, S., Zhang, S., Wang, D. \& Ou, J. 2017. Analysis of Factors Influencing Galloping on the Straddle Sling-Damping Ratio of Long-Span Suspension Bridges. Journal of Vibration and Shock, 08/2017, 36(16), pp. 79-84.

Masoud, Z.N., Nayfeh, A.H. \& Nayfeh, N.A. 2005. Sway Reduction on Quay-Side Container Cranes using Delayed Feedback Controller: Simulations and Experiments. Journal of Vibration and Control Vol. 11, No. 8, pp. 1103-1122.

Nayfeh, A.H., Masoud, Z.N. \& Nayfeh, N.A. 2005. A Delayed-Position Feedback Controller for Cranes. Proceedings of IUTAM Symposium on Chaotic Dynamics and Control of Systems and Processes in Mechanics, Springer, pp. 385-395.

Simiu, E \& Scanlan, R.H. 1996. Wind Effect on Structures: Fundamentals and Applications to Design. John Wiley \& Sons, New York.

Soliman, M.A. \& Ray, W.H. 1992. Optimal Feedback Control for Linear Quadratic System Having Time-Delay. International Journal of Control, 15: 609-615.

Soong, T.T. \& Spencer, B.F. Jr. 2002. Supplemental Energy Dissipation: State - of - the - Art and State - of - the Practice. Engineering Structures, 24: 243-259.

Yang, J.N., Akbar pour, A. \& Askar, G. 1990. Effect of Time-Delay on Control of Seismic Excited Buildings. Journal of Structural Engineering Division ASCE, 116(10): 2801-2814.

Yu, P., Desai, Y.M., Shah, A.H. \& Popplewell, N. 1993. Three-Degree-of-Freedom Model for Galloping. Part 1: Formulation. Journal of Engineering Mechanics ASCE, 119(12): 2404-2425.

Yu, P., Desai, Y.M., Popplewell, N. \& Shah, A.H., 1993. Three-Degree-of-Freedom Model for Galloping. Part 2: Solutions. Journal of Engineering Mechanics ASCE, 119(12): 2426-2448. 


\section{Appendix}

The parameters of equations (16) to (18) are obtained by the integral transformation using equations (7) to (15) as follows:

$$
\begin{aligned}
& \ddot{W}+2 \zeta \omega_{w} \dot{W}+\omega_{w}^{2} W+c_{5} W V+c_{6} W V^{2}+c_{7} W^{3}=F_{w}(t) \\
& \ddot{V}+2 \zeta \omega_{v} \dot{V}+\omega_{v}^{2} V+c_{1} V^{2}+c_{2} W^{2}+c_{3} V^{3}+c_{4} V W^{2}=F_{v}(t) \\
& +c_{11} \times \mathrm{u}(\mathrm{t})+\mathrm{d}_{1} \mathrm{Z}+\mathrm{d}_{2} \mathrm{~V} \\
& \ddot{\mathrm{Z}}+2 \zeta_{\mathrm{B}} \omega_{\mathrm{B}} \dot{\mathrm{Z}}+\omega_{\mathrm{B}}^{2} \mathrm{Z}=\mathrm{F}_{\mathrm{wb}}(\mathrm{t})+\mathrm{c}_{8} \times \mathrm{Z}+\mathrm{c}_{9} \times \mathrm{V}-\mathrm{c}_{10} \times \mathrm{u}(\mathrm{t}) \\
& -c_{10} \times\left[M_{D} \times 2 \zeta_{D} \omega_{D} \times(\dot{P}-\dot{Z})+M_{D} \times \omega_{D}^{2} \times(P-Z)\right] \\
& \ddot{\mathrm{P}}+2 \zeta_{\mathrm{D}} \omega_{\mathrm{D}} \times \dot{\mathrm{P}}+\omega_{\mathrm{D}}^{2} \times \mathrm{P}=2 \zeta_{\mathrm{D}} \omega_{\mathrm{D}} \times \dot{\mathrm{Z}}+\omega_{\mathrm{D}}^{2} \times \mathrm{Z}-\mathrm{c}_{11} \times \mathrm{u}(\mathrm{t}) \\
& \omega_{\mathrm{v}}^{2}=-\frac{\mathrm{H}}{\mathrm{m}} \times \frac{\int_{0}^{\ell^{*}} \phi \times \phi^{\prime \prime} \mathrm{ds}}{\int_{0}^{\ell^{*}} \phi^{2} \mathrm{ds}} ; \quad \omega_{\mathrm{w}}^{2}=-\frac{\mathrm{H}}{\mathrm{m}} \times \frac{\int_{0}^{\ell^{*}} \lambda \times \lambda^{\prime \prime} \mathrm{ds}}{\int_{0}^{\ell^{*}} \lambda^{2} \mathrm{ds}} ; \quad \beta=\frac{\mathrm{mg} \ell^{*}}{\mathrm{H}} \\
& c_{1}=\frac{1.5 \beta E A^{*}}{m \ell^{*}} \times \frac{\int_{0}^{\ell^{*}} \phi \phi^{\prime 2} \mathrm{ds}}{\int_{0}^{\ell^{*}} \phi^{2} \mathrm{ds}} ; \mathrm{c}_{2}=\frac{\beta \mathrm{EA}^{*}}{2 \mathrm{~m} \ell^{*}} \times \frac{\int_{0}^{\ell^{*}} \lambda \lambda^{\prime 2} \mathrm{ds}}{\int_{0}^{\ell^{*}} \phi^{2} \mathrm{ds}} ; \mathrm{c}_{3}=-\frac{1.5 \mathrm{EA}^{*}}{\mathrm{~m}} \times \frac{\int_{0}^{\ell^{*}} \phi \phi^{\prime 2} \phi^{\prime} \mathrm{ds}^{\prime}}{\int_{0}^{\ell^{*}} \phi^{2} \mathrm{ds}} \\
& \mathrm{c}_{4}=-\left(\frac{\mathrm{EA^{* }}}{\mathrm{m} \ell^{*}} \times \frac{\int_{0}^{\ell^{*}} \phi \phi^{\prime} \lambda^{\prime} \lambda^{\prime \prime} \mathrm{ds}}{\int_{0}^{\ell^{*}} \phi^{2} \mathrm{ds}}+\frac{E A^{*}}{2 \mathrm{~m}} \times \frac{\int_{0}^{\ell^{*}} \phi \phi^{\prime \prime} \lambda^{\prime}{ }^{2}}{\int_{0}^{\ell^{*}} \phi^{2} \mathrm{ds}}\right) ; \quad \mathrm{c}_{5}=\frac{E A^{*}}{\mathrm{~m} \ell^{*}} \times \frac{\int_{0}^{\ell^{*}} \phi \lambda \lambda^{\prime \prime} \mathrm{ds}}{\int_{0}^{\ell^{*}} \lambda^{2} \mathrm{ds}} \\
& \mathrm{c}_{6}=-\left(\frac{\mathrm{EA}}{\mathrm{m}} \times \frac{\int_{0}^{\ell^{*}} \lambda \phi^{\prime} \lambda^{\prime} \phi^{\prime \prime} \mathrm{ds}}{\int_{0}^{\ell^{*}} \lambda^{2} \mathrm{ds}}+\frac{\mathrm{EA}^{*}}{2 \mathrm{~m}} \times \frac{\int_{0}^{\ell^{*}} \lambda \lambda^{\prime \prime} \phi^{\prime 2} \mathrm{ds}}{\int_{0}^{\ell^{*}} \lambda^{2} \mathrm{ds}}\right) ; \mathrm{c}_{7}=-\frac{1.5 E A^{*}}{\mathrm{~m}} \times \frac{\int_{0}^{\ell^{*}} \lambda \lambda^{\prime \prime} \lambda^{\prime 2} \mathrm{ds}}{\int_{0}^{\ell^{*}} \lambda^{2} \mathrm{ds}} \\
& \mathrm{c}_{8}=-\sum_{\mathrm{i}=1}^{\mathrm{N}} 2 \times \frac{\mathrm{k}_{\mathrm{i}}}{\mathrm{m}_{\mathrm{b}} \ell} \times \eta^{2}\left(\mathrm{x}_{\mathrm{i}}\right) ; \quad \mathrm{c}_{9}=\sum_{\mathrm{i}=1}^{\mathrm{N}} 2 \times \frac{\mathrm{k}_{\mathrm{i}}}{\mathrm{m}_{\mathrm{b}} \ell} \times \eta\left(\mathrm{x}_{\mathrm{i}}\right) \times \phi\left(\mathrm{s}_{\mathrm{i}}\right) \\
& c_{10}=-\frac{2}{m_{b} \times \ell} ; \quad c_{11}=\frac{2}{m \times \ell^{*}} \quad ; \quad P^{*}=\frac{2 \mathrm{P}}{m_{b} \times \ell} ; \quad \omega_{B}^{2}=\frac{E I}{m_{b}} \times \frac{\int_{0}^{\ell} \eta \eta^{\prime \prime} \mathrm{dx}}{\int_{0}^{\ell} \eta^{2} \mathrm{dx}} \\
& \mathrm{d}_{1}=\sum_{\mathrm{i}=1}^{\mathrm{N}} 2 \times \frac{\mathrm{k}_{\mathrm{i}}}{\mathrm{m} \ell^{*}} \times \eta\left(\mathrm{x}_{\mathrm{i}}\right) \times \phi\left(\mathrm{s}_{\mathrm{i}}\right) ; \quad \mathrm{d}_{2}=-\sum_{\mathrm{i}=1}^{\mathrm{N}} \frac{2 \mathrm{k}_{\mathrm{i}}}{\mathrm{m} \ell^{*}} \times \phi^{2}\left(\mathrm{~s}_{\mathrm{i}}\right)
\end{aligned}
$$

The wind forces $F_{w}(t)$ and $F_{v}(t)$ are obtained from the integral transformation of equations (32) and (33). The data from the wind tunnel tests are fitted with the following polynomials to get the constants $\left(a_{i}\right)$ and $\left(b_{i}\right)$ used to determine the values of $\left(\mathrm{C}_{\mathrm{wi}}\right)$ and $\left(\mathrm{C}_{\mathrm{vi}}\right)$ in equations (34) and (35).

$$
\begin{aligned}
& \mathrm{a}_{\mathrm{o}}=1.17754 ; \mathrm{a}_{1}=0.3544 ; \mathrm{a}_{2}=0.61685 ; \mathrm{a}_{3}=-0.0834 ; \mathrm{a}_{4}=-0.11802 ; \mathrm{a}_{5}=0.004687 ; \mathrm{a}_{6}=0.0031 ; \mathrm{a}_{7}=-0.000075 \\
& \mathrm{~b}_{\mathrm{o}}=-0.14825 ; \mathrm{b}_{1}=-1.36225 ; \mathrm{b}_{2}=0.39288 ; \mathrm{b}_{3}=2.0595 ; \mathrm{b}_{4}=-0.1129 ; \mathrm{b}_{5}=-0.54836 ; \mathrm{b}_{6}=0.003134 ; \mathrm{b}_{7}=0.0151 \\
& \mathrm{C}_{\mathrm{w}}(\gamma)=1.17754+0.3544 \tan \gamma+0.61685 \tan ^{2} \gamma-0.0834 \tan ^{3} \gamma-0.11802 \tan ^{4} \gamma \\
& \quad+0.004687 \tan ^{5} \gamma+0.0031 \tan ^{6} \gamma-0.000075 \tan ^{7} \gamma
\end{aligned}
$$




$$
\begin{aligned}
& \mathrm{C}_{\mathrm{v}}(\gamma)=-0.14825-1.36225 \tan \gamma+0.39288 \tan ^{2} \gamma+2.0595 \tan ^{3} \gamma-0.1129 \tan ^{4} \gamma \\
& -0.54836 \tan ^{5} \gamma+0.003134 \tan ^{6} \gamma+0.0151 \tan ^{7} \gamma \\
& \mathrm{F}_{\mathrm{w}}(\mathrm{t})=\frac{\int_{0}^{\ell^{*}} \lambda(\mathrm{s}) \times \mathrm{F}_{\mathrm{w}}(\mathrm{s}, \mathrm{t}) \mathrm{ds}}{\mathrm{m}_{c} \times \int_{0}^{\ell^{*}} \lambda^{2}(\mathrm{~s}) \mathrm{ds}} \\
& \mathrm{F}_{\mathrm{v}}(\mathrm{t})=\frac{\int_{0}^{\ell^{*}} \phi(\mathrm{s}) \times \mathrm{F}_{\mathrm{v}}(\mathrm{s}, \mathrm{t}) \mathrm{ds}}{\mathrm{m}_{c} \times \int_{0}^{\ell^{*}} \phi^{2}(\mathrm{~s}) \mathrm{ds}} \\
& \mathrm{F}_{\mathrm{w}}(\mathrm{t})=\mathrm{C}_{\mathrm{wo}}+\mathrm{C}_{\mathrm{w} 1} \dot{\mathrm{W}}+\mathrm{C}_{\mathrm{w} 2} \dot{\mathrm{W}}^{2}+\mathrm{C}_{\mathrm{w} 3} \dot{\mathrm{V}}+\mathrm{C}_{\mathrm{w} 4} \dot{\mathrm{W}} \dot{\mathrm{V}}+\mathrm{C}_{\mathrm{w} 5} \dot{\mathrm{V}}^{2} \\
& +\sum_{\mathrm{k}=3}^{\mathrm{N}} \mathrm{C}_{\mathrm{w}(2 \mathrm{k})} \dot{\mathrm{V}}^{\mathrm{k}}+\sum_{\mathrm{k}=3}^{\mathrm{N}} \mathrm{C}_{\mathrm{w}(2 \mathrm{k}+1)} \dot{\mathrm{V}}^{\mathrm{k}} \dot{\mathrm{W}}^{(\mathrm{k}-2)} \\
& \mathrm{F}_{\mathrm{v}}(\mathrm{t})=\mathrm{C}_{\mathrm{vo}}+\mathrm{C}_{\mathrm{v} 1} \dot{\mathrm{W}}+\mathrm{C}_{\mathrm{v} 2} \dot{\mathrm{W}}^{2}+\mathrm{C}_{\mathrm{v} 3} \dot{\mathrm{V}}+\mathrm{C}_{\mathrm{v} 4} \dot{\mathrm{W}} \times \dot{\mathrm{V}}+\mathrm{C}_{\mathrm{v} 5} \dot{\mathrm{V}}^{2} \\
& +\sum_{\mathrm{k}=3}^{\mathrm{N}} \mathrm{C}_{\mathrm{v}(2 \mathrm{k})} \dot{\mathrm{V}}^{\mathrm{k}}+\sum_{\mathrm{k}=3}^{\mathrm{N}} \mathrm{C}_{\mathrm{v}(2 \mathrm{k}+1)} \dot{\mathrm{V}}^{\mathrm{k}} \times \dot{\mathrm{W}}^{(\mathrm{k}-2)}
\end{aligned}
$$

\section{Coefficients of the Wind Force, $F_{w}(t)$}

$$
\begin{aligned}
& \mathrm{C}_{\mathrm{w} 0}=\frac{\rho \times \mathrm{D} \times \mathrm{a}_{0}}{2 \mathrm{~m}} \times \frac{\int_{0}^{\ell^{*}} \lambda(\mathrm{s}) \times \mathrm{U}_{0}^{2} \times \mathrm{ds}}{\int_{0}^{\ell^{*}} \lambda^{2}(\mathrm{~s}) \times \mathrm{ds}} ; \mathrm{C}_{\mathrm{w} 1}=-\frac{\rho \times \mathrm{D} \times \mathrm{a}_{0}}{\mathrm{~m}} \times \frac{\int_{0}^{\ell^{*}} \lambda^{2}(\mathrm{~s}) \times \mathrm{U}_{0} \times \mathrm{ds}}{\int_{0}^{\ell^{*}} \lambda^{2}(\mathrm{~s}) \times \mathrm{ds}} \\
& \mathrm{C}_{\mathrm{w} 2}=\frac{\rho \times \mathrm{D} \times \mathrm{a}_{0}}{2 \mathrm{~m}} \times \frac{\int_{0}^{\ell^{*}} \lambda^{3}(\mathrm{~s}) \times \mathrm{ds}}{\int_{0}^{\ell^{*}} \lambda^{2}(\mathrm{~s}) \times \mathrm{ds}} ; \quad \mathrm{C}_{\mathrm{w} 3}=\frac{\rho \times \mathrm{D} \times \mathrm{a}_{1}}{2 \mathrm{~m}} \times \frac{\int_{0}^{\ell^{*}} \lambda(\mathrm{s}) \times \phi(\mathrm{s}) \times \mathrm{U}_{0} \times \mathrm{ds}}{\int_{0}^{\ell^{*}} \lambda^{2}(\mathrm{~s}) \times \mathrm{ds}} \\
& \mathrm{C}_{\mathrm{w} 4}=-\frac{\rho \times \mathrm{D} \times \mathrm{a}_{1}}{2 \mathrm{~m}} \times \frac{\int_{0}^{\ell^{*}} \lambda^{2}(\mathrm{~s}) \times \phi(\mathrm{s}) \times \mathrm{ds}}{\int_{0}^{\ell^{*}} \lambda^{2}(\mathrm{~s}) \times \mathrm{ds}} ; \quad \mathrm{C}_{\mathrm{w} 5}=\frac{\rho \times \mathrm{D} \times \mathrm{a}_{2}}{2 \mathrm{~m}} \times \frac{\int_{0}^{\ell^{*}} \lambda(\mathrm{s}) \times \phi^{2}(\mathrm{~s}) \times \mathrm{ds}}{\int_{0}^{\ell^{*}} \lambda^{2}(\mathrm{~s}) \times \mathrm{ds}} \\
& \mathrm{C}_{\mathrm{w} 6}=\frac{\rho \times \mathrm{D} \times \mathrm{a}_{3}}{2 \mathrm{~m}} \times \frac{\int_{0}^{\ell^{*}} \lambda(\mathrm{s}) \times \phi(\mathrm{s})^{3} \times \mathrm{ds}}{\mathrm{U}_{0} \int_{0}^{\ell^{*}} \lambda^{2}(\mathrm{~s}) \times \mathrm{ds}} ; \mathrm{C}_{\mathrm{w} 7}=\frac{\rho \times \mathrm{D} \times \mathrm{a}_{3}}{2 \mathrm{~m}} \times \frac{\int_{0}^{\ell^{*}} \phi^{3}(\mathrm{~s}) \times \lambda^{2}(\mathrm{~s}) \times \mathrm{ds}}{\mathrm{U}_{0}^{2} \int_{0}^{\ell^{*}} \lambda^{2}(\mathrm{~s}) \times \mathrm{ds}} \\
& \mathrm{C}_{\mathrm{w} 8}=\frac{\rho \times \mathrm{D} \times \mathrm{a}_{3}}{2 \mathrm{~m}} \times \frac{\int_{0}^{\ell^{*}} \lambda^{3}(\mathrm{~s}) \times \phi^{3}(\mathrm{~s}) \times \mathrm{ds}}{\mathrm{U}_{0}^{3} \int_{0}^{\ell^{*}} \lambda^{2}(\mathrm{~s}) \times \mathrm{ds}} ; \mathrm{C}_{\mathrm{w} 9}=\frac{\rho \times \mathrm{D} \times \mathrm{a}_{3}}{2 \mathrm{~m}} \times \frac{\int_{0}^{\ell^{*}} \lambda^{4}(\mathrm{~s}) \times \phi^{3}(\mathrm{~s}) \times \mathrm{ds}}{\mathrm{U}_{0}^{4} \int_{0}^{\ell^{*}} \lambda^{2}(\mathrm{~s}) \times \mathrm{ds}} \\
& \mathrm{C}_{\mathrm{w} 10}=\frac{\rho \times \mathrm{D} \times \mathrm{a}_{4}}{2 \mathrm{~m}} \times \frac{\int_{0}^{\ell^{*}} \lambda^{4}(\mathrm{~s}) \times \phi^{3}(\mathrm{~s}) \times \mathrm{ds}}{\mathrm{U}_{0}^{4} \int_{0}^{\ell^{*}} \lambda^{2}(\mathrm{~s}) \times \mathrm{ds}} ; \mathrm{C}_{\mathrm{w} 11}=\frac{\rho \times \mathrm{D} \times \mathrm{a}_{4}}{2 \mathrm{~m}} \times \frac{\int_{0}^{\ell^{*}} \lambda^{2}(\mathrm{~s}) \times \phi^{4}(\mathrm{~s}) \times \mathrm{ds}}{\mathrm{U}_{0}^{3} \int_{0}^{\ell^{*}} \lambda^{2}(\mathrm{~s}) \times \mathrm{ds}} \\
& \mathrm{C}_{\mathrm{w} 12}=\frac{\rho \times \mathrm{D} \times \mathrm{a}_{4}}{2 \mathrm{~m}} \times \frac{\int_{0}^{\ell^{*}} \lambda^{3}(\mathrm{~s}) \times \phi^{4}(\mathrm{~s}) \times \mathrm{ds}}{\mathrm{U}_{0}^{4} \int_{0}^{\ell^{*}} \lambda^{2}(\mathrm{~s}) \times \mathrm{ds}} ; \mathrm{C}_{\mathrm{w} 13}=\frac{\rho \times \mathrm{D} \times \mathrm{a}_{4}}{2 \mathrm{~m}} \times \frac{\int_{0}^{\ell^{*}} \lambda^{4}(\mathrm{~s}) \times \phi^{4}(\mathrm{~s}) \times \mathrm{ds}}{\mathrm{U}_{0}^{5} \int_{0}^{\ell^{*}} \lambda^{2}(\mathrm{~s}) \times \mathrm{ds}}
\end{aligned}
$$


$\mathrm{C}_{\mathrm{w} 14}=\frac{\rho \times \mathrm{D} \times \mathrm{a}_{5}}{2 \mathrm{~m}} \times \frac{\int_{0}^{\ell^{*}} \lambda(\mathrm{s}) \times \phi^{5}(\mathrm{~s}) \times \mathrm{ds}}{\mathrm{U}_{0}^{3} \int_{0}^{\ell^{*}} \lambda^{2}(\mathrm{~s}) \times \mathrm{ds}} ; \quad \mathrm{C}_{\mathrm{w} 15}=\frac{\rho \times \mathrm{D} \times \mathrm{a}_{5}}{2 \mathrm{~m}} \times \frac{\int_{0}^{\ell^{*}} \lambda^{2}(\mathrm{~s}) \times \phi^{5}(\mathrm{~s}) \times \mathrm{ds}}{\mathrm{U}_{0}^{4} \int_{0}^{\ell^{*}} \lambda^{2}(\mathrm{~s}) \times \mathrm{ds}}$

$\mathrm{C}_{\mathrm{w} 16}=\frac{\rho \times \mathrm{D} \times \mathrm{a}_{5}}{2 \mathrm{~m}} \times \frac{\int_{0}^{\ell^{*}} \lambda^{3}(\mathrm{~s}) \times \phi^{5}(\mathrm{~s}) \times \mathrm{ds}}{\mathrm{U}_{0}^{5} \int_{0}^{\ell^{*}} \lambda^{2}(\mathrm{~s}) \times \mathrm{ds}} ; \mathrm{C}_{\mathrm{w} 17}=\frac{\rho \times \mathrm{D} \times \mathrm{a}_{5}}{2 \mathrm{~m}} \times \frac{\int_{0}^{\ell^{*}} \lambda^{4}(\mathrm{~s}) \times \phi^{5}(\mathrm{~s}) \times \mathrm{ds}}{\mathrm{U}_{0}^{6} \int_{0}^{\ell^{*}} \lambda^{2}(\mathrm{~s}) \times \mathrm{ds}}$

$\mathrm{C}_{\mathrm{w} 18}=\frac{\rho \times \mathrm{D} \times \mathrm{a}_{6}}{2 \mathrm{~m}} \times \frac{\int_{0}^{\ell^{*}} \lambda(\mathrm{s}) \times \phi^{6}(\mathrm{~s}) \times \mathrm{ds}}{\mathrm{U}_{0}^{4} \int_{0}^{\ell^{*}} \lambda^{2}(\mathrm{~s}) \times \mathrm{ds}} ; \quad \mathrm{C}_{\mathrm{w} 19}=\frac{\rho \times \mathrm{D} \times \mathrm{a}_{6}}{2 \mathrm{~m}} \times \frac{\int_{0}^{\ell^{*}} \lambda^{2}(\mathrm{~s}) \times \phi^{6}(\mathrm{~s}) \times \mathrm{ds}}{\mathrm{U}_{0}^{5} \int_{0}^{\ell^{*}} \lambda^{2}(\mathrm{~s}) \times \mathrm{ds}}$

$\mathrm{C}_{\mathrm{w} 20}=\frac{\rho \times \mathrm{D} \times \mathrm{a}_{6}}{2 \mathrm{~m}} \times \frac{\int_{0}^{\ell^{*}} \lambda^{3}(\mathrm{~s}) \times \phi^{6}(\mathrm{~s}) \times \mathrm{ds}}{\mathrm{U}_{0}^{6} \int_{0}^{\ell^{*}} \lambda^{2}(\mathrm{~s}) \times \mathrm{ds}} ; \mathrm{C}_{\mathrm{w} 21}=\frac{\rho \times \mathrm{D} \times \mathrm{a}_{6}}{2 \mathrm{~m}} \times \frac{\int_{0}^{\ell^{*}} \lambda^{4}(\mathrm{~s}) \times \phi^{6}(\mathrm{~s}) \times \mathrm{ds}}{\mathrm{U}_{0}^{7} \int_{0}^{\ell^{*}} \lambda^{2}(\mathrm{~s}) \times \mathrm{ds}}$

$\mathrm{C}_{\mathrm{w} 22}=\frac{\rho \times \mathrm{D} \times \mathrm{a}_{7}}{2 \mathrm{~m}} \times \frac{\int_{0}^{\ell^{*}} \lambda(\mathrm{s}) \times \phi^{7}(\mathrm{~s}) \times \mathrm{ds}}{\mathrm{U}_{0}^{5} \int_{0}^{\ell^{*}} \lambda^{2}(\mathrm{~s}) \times \mathrm{ds}} ; \quad \mathrm{C}_{\mathrm{w} 23}=\frac{\rho \times \mathrm{D} \times \mathrm{a}_{7}}{2 \mathrm{~m}} \times \frac{\int_{0}^{\ell^{*}} \lambda^{2}(\mathrm{~s}) \times \phi^{7}(\mathrm{~s}) \times \mathrm{ds}}{\mathrm{U}_{0}^{6} \int_{0}^{\ell^{*}} \lambda^{2}(\mathrm{~s}) \times \mathrm{ds}}$

$\mathrm{C}_{\mathrm{w} 24}=\frac{\rho \times \mathrm{D} \times \mathrm{a}_{7}}{2 \mathrm{~m}} \times \frac{\int_{0}^{\ell^{*}} \lambda^{3}(\mathrm{~s}) \times \phi^{7}(\mathrm{~s}) \times \mathrm{ds}}{\mathrm{U}_{0}^{7} \int_{0}^{\ell^{*}} \lambda^{2}(\mathrm{~s}) \times \mathrm{ds}} ; \quad \mathrm{C}_{\mathrm{w} 25}=\frac{\rho \times \mathrm{D} \times \mathrm{a}_{7}}{2 \mathrm{~m}} \times \frac{\int_{0}^{\ell^{*}} \lambda^{4}(\mathrm{~s}) \times \phi^{7}(\mathrm{~s}) \times \mathrm{ds}}{\mathrm{U}_{0}^{8} \int_{0}^{\ell^{*}} \lambda^{2}(\mathrm{~s}) \times \mathrm{ds}}$

\section{Coefficients of Wind Force, $F_{v}(t)$}

$\mathrm{C}_{\mathrm{v} 0}=\frac{\rho \times \mathrm{D} \times \mathrm{b}_{0}}{2 \mathrm{~m}} \times \frac{\int_{0}^{\ell^{*}} \phi(\mathrm{s}) \times \mathrm{U}_{0}^{2} \times \mathrm{ds}}{\int_{0}^{\ell^{*}} \phi^{2}(\mathrm{~s}) \times \mathrm{ds}} ; \mathrm{C}_{\mathrm{v} 1}=(-) \frac{\rho \times \mathrm{D} \times \mathrm{b}_{0}}{2 \mathrm{~m}} \times \frac{\int_{0}^{\ell^{*}} \phi(\mathrm{s}) \times \lambda(\mathrm{s}) \times \mathrm{U}_{0} \times \mathrm{ds}}{\mathrm{U}_{0}^{2} \int_{0}^{\ell^{*}} \phi^{2}(\mathrm{~s}) \times \mathrm{ds}}$

$\mathrm{C}_{\mathrm{v} 2}=\frac{\rho \times \mathrm{D} \times \mathrm{b}_{0}}{2 \mathrm{~m}} \times \frac{\int_{0}^{\ell^{*}} \phi(\mathrm{s}) \times \lambda^{2}(\mathrm{~s}) \times \mathrm{ds}}{\int_{0}^{\ell^{*}} \phi^{2}(\mathrm{~s}) \times \mathrm{ds}} ; \quad \mathrm{C}_{\mathrm{v} 3}=\frac{\rho \times \mathrm{D} \times \mathrm{b}_{1}}{2 \mathrm{~m}} \times \frac{\int_{0}^{\ell^{*}} \phi^{2}(\mathrm{~s}) \times \mathrm{U}_{0} \times \mathrm{ds}}{\int_{0}^{\ell^{*}} \phi^{2}(\mathrm{~s}) \times \mathrm{ds}}$

$\mathrm{C}_{\mathrm{v} 4}=(-) \frac{\rho \times \mathrm{D} \times \mathrm{b}_{1}}{2 \mathrm{~m}} \times \frac{\int_{0}^{\ell^{*}} \phi^{2}(\mathrm{~s}) \times \lambda(\mathrm{s}) \times \mathrm{ds}}{\int_{0}^{\ell^{*}} \phi^{2}(\mathrm{~s}) \times \mathrm{ds}} ; \quad \mathrm{C}_{\mathrm{v} 5}=\frac{\rho \times \mathrm{D} \times \mathrm{b}_{2}}{2 \mathrm{~m}} \times \frac{\int_{0}^{\ell^{*}} \phi^{3}(\mathrm{~s}) \times \mathrm{ds}}{\int_{0}^{\ell^{*}} \phi^{2}(\mathrm{~s}) \times \mathrm{ds}}$

$\mathrm{C}_{\mathrm{v} 6}=\frac{\rho \times \mathrm{D} \times \mathrm{b}_{3}}{2 \mathrm{~m}} \times \frac{\int_{0}^{\ell^{*}} \phi^{4}(\mathrm{~s}) \times \mathrm{ds}}{\mathrm{U}_{0} \int_{0}^{\ell^{*}} \phi^{2}(\mathrm{~s}) \times \mathrm{ds}} ; \quad \mathrm{C}_{\mathrm{v} 7}=\frac{\rho \times \mathrm{D} \times \mathrm{b}_{3}}{2 \mathrm{~m}} \times \frac{\int_{0}^{\ell^{*}} \phi^{4}(\mathrm{~s}) \times \lambda(\mathrm{s}) \times \mathrm{ds}}{\mathrm{U}_{0}^{3} \int_{0}^{\ell^{*}} \phi^{2}(\mathrm{~s}) \times \mathrm{ds}}$

$\mathrm{C}_{\mathrm{v} 8}=\frac{\rho \times \mathrm{D} \times \mathrm{b}_{3}}{2 \mathrm{~m}} \times \frac{\int_{0}^{\ell^{*}} \phi^{4}(\mathrm{~s}) \times \lambda^{2}(\mathrm{~s}) \times \mathrm{ds}}{\mathrm{U}_{0}^{3} \int_{0}^{\ell^{*}} \phi^{2}(\mathrm{~s}) \times \mathrm{ds}} ; \quad \mathrm{C}_{\mathrm{v} 9}=\frac{\rho \times \mathrm{D} \times \mathrm{b}_{3}}{2 \mathrm{~m}} \times \frac{\int_{0}^{\ell^{*}} \phi^{4}(\mathrm{~s}) \times \lambda^{3}(\mathrm{~s}) \times \mathrm{ds}}{\mathrm{U}_{0}^{4} \int_{0}^{\ell^{*}} \phi^{2}(\mathrm{~s}) \times \mathrm{ds}}$

$\mathrm{C}_{\mathrm{v} 10}=\frac{\rho \times \mathrm{D} \times \mathrm{b}_{4}}{2 \mathrm{~m}} \times \frac{\int_{0}^{\ell^{*}} \phi^{5}(\mathrm{~s}) \times \mathrm{ds}}{\mathrm{U}_{0}^{2} \int_{0}^{\ell^{*}} \phi^{2}(\mathrm{~s}) \times \mathrm{ds}} ; \quad \mathrm{C}_{\mathrm{v} 11}=\frac{\rho \times \mathrm{D} \times \mathrm{b}_{4}}{2 \mathrm{~m}} \times \frac{\int_{0}^{\ell^{*}} \phi^{5}(\mathrm{~s}) \times \lambda(\mathrm{s}) \times \mathrm{ds}}{\mathrm{U}_{0}^{3} \int_{0}^{\ell^{*}} \phi^{2}(\mathrm{~s}) \times \mathrm{ds}}$ 
42

Effect of the time delay on the magnitude of the onset galloping wind speed in semiactive controlled suspension bridges

$$
\begin{aligned}
& \mathrm{C}_{\mathrm{v} 12}=\frac{\rho \times \mathrm{D} \times \mathrm{b}_{4}}{2 \mathrm{~m}} \times \frac{\int_{0}^{\ell^{*}} \phi^{5}(\mathrm{~s}) \times \lambda^{2}(\mathrm{~s}) \times \mathrm{ds}}{\mathrm{U}_{0}^{2} \int_{0}^{\ell^{*}} \phi^{2}(\mathrm{~s}) \times \mathrm{ds}} ; \quad \mathrm{C}_{\mathrm{v} 13}=\frac{\rho \times \mathrm{D} \times \mathrm{b}_{4}}{2 \mathrm{~m}} \times \frac{\int_{0}^{\ell^{*}} \phi^{5}(\mathrm{~s}) \times \lambda^{3}(\mathrm{~s}) \times \mathrm{ds}}{\mathrm{U}_{0}^{3} \int_{0}^{\ell^{*}} \phi^{2}(\mathrm{~s}) \times \mathrm{ds}} \\
& \mathrm{C}_{\mathrm{v} 14}=\frac{\rho \times \mathrm{D} \times \mathrm{b}_{5}}{2 \mathrm{~m}} \times \frac{\int_{0}^{\ell^{*}} \phi^{6}(\mathrm{~s}) \times \mathrm{ds}}{\mathrm{U}_{0}^{3} \int_{0}^{\ell^{*}} \phi^{2}(\mathrm{~s}) \times \mathrm{ds}} ; \quad \mathrm{C}_{\mathrm{v} 15}=\frac{\rho \times \mathrm{D} \times \mathrm{b}_{5}}{2 \mathrm{~m}} \times \frac{\int_{0}^{\ell^{*}} \phi^{6}(\mathrm{~s}) \times \lambda(\mathrm{s}) \times \mathrm{ds}}{\mathrm{U}_{0}^{4} \int_{0}^{\ell^{*}} \phi^{2}(\mathrm{~s}) \times \mathrm{ds}} \\
& \mathrm{C}_{\mathrm{v} 16}=\frac{\rho \times \mathrm{D} \times \mathrm{b}_{5}}{2 \mathrm{~m}} \times \frac{\int_{0}^{\ell^{*}} \phi^{6}(\mathrm{~s}) \times \lambda^{2}(\mathrm{~s}) \times \mathrm{ds}}{\mathrm{U}_{0}^{5} \int_{0}^{\ell^{*}} \phi^{2}(\mathrm{~s}) \times \mathrm{ds}} ; \mathrm{C}_{\mathrm{v} 17}=\frac{\rho \times \mathrm{D} \times \mathrm{b}_{5}}{2 \mathrm{~m}} \times \frac{\int_{0}^{\ell^{*}} \phi^{6}(\mathrm{~s}) \times \lambda^{2}(\mathrm{~s}) \times \mathrm{ds}}{\mathrm{U}_{0}^{6} \int_{0}^{\ell^{*}} \phi^{2}(\mathrm{~s}) \times \mathrm{ds}} \\
& \mathrm{C}_{\mathrm{v} 18}=\frac{\rho \times \mathrm{D} \times \mathrm{b}_{6}}{2 \mathrm{~m}} \times \frac{\int_{0}^{\ell^{*}} \phi^{7}(\mathrm{~s}) \times \mathrm{ds}}{\mathrm{U}_{0}^{4} \int_{0}^{\ell^{*}} \phi^{2}(\mathrm{~s}) \times \mathrm{ds}} ; \quad \mathrm{C}_{\mathrm{v} 19}=\frac{\rho \times \mathrm{D} \times \mathrm{b}_{6}}{2 \mathrm{~m}} \times \frac{\int_{0}^{\ell^{*}} \phi^{7}(\mathrm{~s}) \times \lambda(\mathrm{s}) \times \mathrm{ds}}{\mathrm{U}_{0}^{5} \int_{0}^{\ell^{*}} \phi^{2}(\mathrm{~s}) \times \mathrm{ds}} \\
& \mathrm{C}_{\mathrm{v} 20}=\frac{\rho \times \mathrm{D} \times \mathrm{b}_{6}}{2 \mathrm{~m}} \times \frac{\int_{0}^{\ell^{*}} \phi^{7}(\mathrm{~s}) \times \lambda^{2}(\mathrm{~s}) \times \mathrm{ds}}{\mathrm{U}_{0}^{6} \int_{0}^{\ell^{*}} \phi^{2}(\mathrm{~s}) \times \mathrm{ds}} ; \mathrm{C}_{\mathrm{v} 21}=\frac{\rho \times \mathrm{D} \times \mathrm{b}_{6}}{2 \mathrm{~m}} \times \frac{\int_{0}^{\ell^{*}} \phi^{7}(\mathrm{~s}) \times \lambda^{3}(\mathrm{~s}) \times \mathrm{ds}}{\mathrm{U}_{0}^{7} \int_{0}^{\ell^{*}} \phi^{2}(\mathrm{~s}) \times \mathrm{ds}} \\
& \mathrm{C}_{\mathrm{v} 22}=\frac{\rho \times \mathrm{D} \times \mathrm{b}_{7}}{2 \mathrm{~m}} \times \frac{\int_{0}^{\ell^{*}} \phi^{8}(\mathrm{~s}) \times \mathrm{ds}}{\mathrm{U}_{0}^{5} \int_{0}^{\ell^{*}} \phi^{2}(\mathrm{~s}) \times \mathrm{ds}} ; \quad \mathrm{C}_{\mathrm{v} 23}=\frac{\rho \times \mathrm{D} \times \mathrm{b}_{7}}{2 \mathrm{~m}} \times \frac{\int_{0}^{\ell^{*}} \phi^{8}(\mathrm{~s}) \times \lambda(\mathrm{s}) \times \mathrm{ds}}{\mathrm{U}_{0}^{6} \int_{0}^{\ell^{*}} \phi^{2}(\mathrm{~s}) \times \mathrm{ds}} \\
& \mathrm{C}_{\mathrm{v} 24}=\frac{\rho \times \mathrm{D} \times \mathrm{b}_{7}}{2 \mathrm{~m}} \times \frac{\int_{0}^{\ell^{*}} \phi^{8}(\mathrm{~s}) \times \lambda^{2}(\mathrm{~s}) \times \mathrm{ds}}{\mathrm{U}_{0}^{7} \int_{0}^{\ell^{*}} \phi^{2}(\mathrm{~s}) \times \mathrm{ds}} ; \mathrm{C}_{\mathrm{v} 25}=\frac{\rho \times \mathrm{D} \times \mathrm{b}_{7}}{2 \mathrm{~m}} \times \frac{\int_{0}^{\ell^{*}} \phi^{8}(\mathrm{~s}) \times \lambda^{3}(\mathrm{~s}) \times \mathrm{ds}}{\mathrm{U}_{0}^{8} \int_{0}^{\ell^{*}} \phi^{2}(\mathrm{~s}) \times \mathrm{ds}}
\end{aligned}
$$

